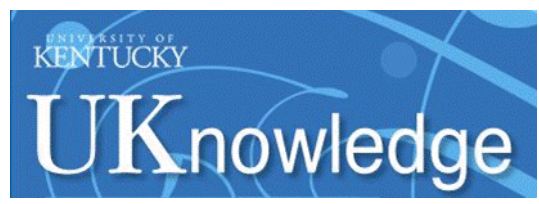

University of Kentucky

UKnowledge

$12-2018$

\title{
Morphometric Characteristics and Time to Hatch as Efficacious Indicators for Potential Nanotoxicity Assay in Zebrafish
}

Seyed-Mohammadreza Samaee

Urmia University, Iran

Nafiseh Manteghi

National Institute of Genetic Engineering and Biotechnology, Iran

Robert A. Yokel

University of Kentucky, ryokel@email.uky.edu

Mohammad Reza Mohajeri-Tehrani

Tehran University of Medical Sciences, Iran

Right click to open a feedback form in a new tab to let us know how this document benefits you.

Follow this and additional works at: https://uknowledge.uky.edu/ps_facpub

Part of the Endocrinology, Diabetes, and Metabolism Commons, Food Science Commons, Genetics and Genomics Commons, and the Pharmacy and Pharmaceutical Sciences Commons 


\title{
Morphometric Characteristics and Time to Hatch as Efficacious Indicators for Potential Nanotoxicity Assay in Zebrafish
}

\author{
Digital Object Identifier (DOI) \\ https://doi.org/10.1002/etc.4266 \\ Notes/Citation Information \\ Published in Environmental Toxicology and Chemistry, v. 37, issue 12. \\ (c) 2018 SETAC
}

This is the peer reviewed version of the following article: Samaee, S.-M., Manteghi, N., Yokel, R. A., \& Mohajeri-Tehrani, M. R. (2018). Morphometric characteristics and time to hatch as efficacious indicators for potential nanotoxicity assay in zebrafish: Zebrafish morphology and hatch time indicate nanotoxicity. Environmental Toxicology and Chemistry, 37(12), 3063-3076, which has been published in final form at https://doi.org/10.1002/etc.4266.

This article may be used for non-commercial purposes in accordance with Wiley Terms and Conditions for Use of Self-Archived Versions. This article may not be enhanced, enriched or otherwise transformed into a derivative work, without express permission from Wiley or by statutory rights under applicable legislation. Copyright notices must not be removed, obscured or modified. The article must be linked to Wiley's version of record on Wiley Online Library and any embedding, framing or otherwise making available the article or pages thereof by third parties from platforms, services and websites other than Wiley Online Library must be prohibited. 


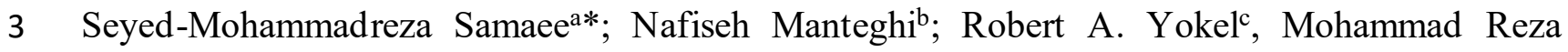

4 Mohajeri-Tehranid $^{\mathrm{d}}$

5

6

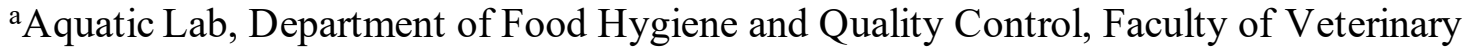
Medicine, Urmia University, Urmia 165, Iran;

8

16
18 9

*Corresponding author: Seyed-Mohammadreza Samaee; Tel: +98-044-32770508; E-mail: seyedmohammadreza.samaee@gmail.com \& mohammadreza_samaee@yahoo.com; ORCID: 0000-0002-9104-0299 Tehran 14114 13137, Iran

Running head: Zebrafish morphology \& hatch time indicate nanotoxicity 0

1


24 Abstract. Although the effects of nanosized titania $\left(\mathrm{nTiO}_{2}\right)$ on hatching events (change in

25 hatching time and total hatching) in zebrafish have been reported, additional consequences of $26 \mathrm{nTiO}_{2}$ exposure, i.e. the effects of $\mathrm{nTiO}_{2}$-induced changes in hatching events and morphometric 27 parameters on embryo-larvae development and survivability have not been reported. To address 28 this knowledge gap, embryos 4 h post-fertilization were exposed to $\mathrm{nTiO}_{2}(0,0.01,10$, and 1000 $29 \mu \mathrm{g} / \mathrm{mL}$ ) for $220 \mathrm{~h}$. Hatching rate (HR; 58, 82, and 106 hours postexposure [hpe]), survival rate 30 (SR; 8 times from 34 to 202 hpe), and 21 morphometric characteristics (MCs; 8 times from 34 to $31202 \mathrm{hpe}$ ) were recorded. Total hatching (HR at $106 \mathrm{hpe}$ ) was significantly and positively 32 correlated to $\mathrm{SR}$, but there was no direct association between $\mathrm{nTiO}_{2}$-induced change in hatching 33 time (HR at 58 and $82 \mathrm{hpe}$ ) and SR. MCs were significantly correlated to HR at 58, 82, and 106 34 hpe, suggesting the $\mathrm{nTiO}_{2}$-induced change in hatching time can affect larval development. The 35 MCs that were associated with change in hatching time were also significantly correlated to SR, 36 suggesting an indirect significant influence of the $\mathrm{nTiO}_{2}$-induced change in hatching time on 37 survivability. These results show a significant influence of $\mathrm{nTiO}_{2}$-induced change in hatching 38 events on zebrafish embryo-larvae development and survivability. They also show that

39

40 41 of $\mathrm{nTiO}_{2}$ acute toxicity.

42

43 44 45 46 embryo-larvae morphometric maldevelopments can predict later-in-life consequences (survivability) of an embryonic exposure to $\mathrm{nTiO}_{2}$. This suggests that zebrafish can be sensitive biological predictors

Keywords: Hatchability, Morphometric characteristics, NM-105, Survivability, Zebrafish 
Metal oxide nanoparticles (MNP), similar to other particles at the nanoscale (1-100 nm

[Colvin 2003]), have unique physicochemical properties compared to parent metals that can

49 induce adverse and unique effects in aquatic organisms (Lovern and Klaper 2006; Moore 2006;

50 Griffitt et al. 2009). MNPs are considered to be an emerging class of environmental pollutants

51 (Service 2004). MNPs possess multiple mechanisms of toxicity that can affect multiple levels of

52 biological organization (Metcalfe et al. 2009).

$\mathrm{Nano}_{-\mathrm{TiO}_{2}}\left(\mathrm{nTiO}_{2}\right)$ is a MNP that has frequent use and widespread industrial applications

54 (Jovanović et al. 2011b). As such, there is the potential for environmental contamination and exposure to $\mathrm{nTiO}_{2}$ (Hall et al. 2009). $\mathrm{nTiO}_{2}$ is a suspected group 2B human carcinogen (Jovanović et al. 2011b). In response to the concerns mentioned above, many studies have

57 investigated the adverse effects of $\mathrm{nTiO}_{2}$ aqueous suspensions on the environment, wildlife, and

58 human health (Menard et al. 2011).

59 The impact of $\mathrm{nTiO}_{2}$ exposure on zebrafish hatching events has been investigated and reported as premature (Kovrižnych et al. 2013; Ma and Diamond 2013; Fouqueray et al. 2013;

61 Samaee et al. 2015) or delayed hatching (Yeo and Jo 2007; Xu et al. 2012). There are also other 62 studies (e.g. Jovanović et al. 2015; Clemente et al. 2014; Wang et al. 2014; Yan et al. 2014) in 63 which viability parameters (e.g. hatching events and/or survivability) have been considered to 64 characterize $\mathrm{nTiO}_{2}$-induced toxicity. These reports warrant further study to identify aspects of $65 \mathrm{nTiO}_{2}$-induced changes in hatching events in relation to zebrafish embryo-larvae development 66 and survivability.

68 responses assessed in zebrafish embryo and larvae toxicology (e.g. see Bar-Ilan et al. 2009) but 69 phenotypic characterization is also very amenable to automation and high throughput (Vogt et al. 


85

8

2009; Liu et al. 2012). In previous studies, the phenotypic analyses of nTiO 2 -induced defects have been performed based upon morphological characteristics (qualitative signs that include dorsal curvature, kinked tail, edema, elongated heart, and others) (Yeo and Kang 2009; Bar-Ilan et al. 2009; Yeo and Kim 2010; He et al. 2014; Wang et al. 2014; Yan et al. 2014). However, generating quantitative data from morphometric characteristics (MC) has been largely ignored or under-used in toxicology assays.

The current study objectives were: 1) to test the hypothesis whether the viability parameters such as hatching events and survivability, as well as morphometric characteristics can characterize the $\mathrm{nTiO}_{2}$-induced toxicity in zebrafish embryo-larvae, 2) to evaluate if $\mathrm{nTiO}_{2}$ induced changes in hatching events (as sub-lethal endpoints) are significantly correlated to embryo-larvae morphometric alterations (as another sub-lethal endpoint that is also accounted for as a criterion for larval development) and survivability (as an acute endpoint), both during $\mathrm{nTiO}_{2}$ exposure and after $\mathrm{nTiO}_{2}$ depuration, and 3) to test the hypothesis that $\mathrm{nTiO}_{2}$-induced changes in sub-lethal endpoints (i.e. hatching events and MCs) can predict later-in-life consequences of zebrafish embryonic/larval exposure.

\section{Materials and methods}

2.1. Zebrafish source and housing

Wild-type zebrafish were purchased from a local supplier in the North of Iran (local suppliers are the only source of wild-type zebrafish here), and maintained in a semi-static system. They were housed in covered glass tanks $(50 \mathrm{~cm} \mathrm{~L} \times 30 \mathrm{~cm} \mathrm{~W} \times 30 \mathrm{~cm} \mathrm{H})$. The tanks were aerated and equipped with a sponge filtration unit, a $150 \mathrm{~W}$ submersible heater (Atman $\AA$, China), and a $6 \mathrm{~W}$ white light (DGL-1540 S-M, Bohem Ltd. Co., China) located on the lid of the 
tank. Municipal (tap) water was dechlorinated and adjusted to $28{ }^{\circ} \mathrm{C}$ after filtration through an active carbon filter (a fully submersible sponge filter [WP, 1150F, Sobo®, China] in which its sponge was replaced with activated carbon [C-300, Aleas ${ }^{\circledR}$, China]). After filtration, water was conditioned with $240 \mathrm{mg} / \mathrm{L}$ rock salt $+60 \mathrm{mg} / \mathrm{L}$ sea salt (Westerfield 2000).

\subsection{Zebrafish maintenance}

After determination of sex (Braunbeck and Lammer 2006), males and females were segregated and housed on a 14:10 h light:dark cycle (9:00 a.m. on, 11:00 p.m. off) (Westerfield 2000). Adult zebrafish were fed a combination of several types of food depending on their development stage and age (flake food Vitakraft ${ }^{\circledR}$ and TetraMin ${ }^{\circledR}$, Germany; and BioMar and live food - brine shrimp Nauplii) to satiation twice a day (Lawrence 2007). Zebrafish larvae from day 2 (34 hours postexposure [hpe]) to 6 (130 hpe) grew on yolk nutrients and were not fed, while from day 6 to day 9 (202 hpe) larvae were fed Paramecium spp. twice daily as described by Varga (2011).

\subsection{Zebrafish spawning and embryo collection}

Healthy males and females (6-18 months old) were segregated one week before breeding. Two males and 3 females were transferred to mating tanks (FH-101, Guangdong boyu aquarium industries Co., Ltd, China) late in the afternoon the day before spawning. Males and females were housed in different chambers, separated by a transparent plastic divider in the mating cage. At 9:00 $\mathrm{h}$ the divider was removed and the zebrafish mated and spawned. Embryos were siphoned from the bottom of the spawning tank into a Petri dish containing conditioned system water (see section 2.1). Methylene blue $(0.5 \mathrm{mg} / \mathrm{L})$ was added to the embryo rearing 
116 medium to prevent fungi growth. Live embryos were collected at $\sim 2$ hours post-fertilization

117 (hpf; blastula stage) (Fouqueray et al. 2013).

118

119 2.4. The $\mathrm{nTiO}_{2}$ nanopowder

120

Degussa P-25 titanium dioxide nanopowder (NM-105) was obtained from Evonik

121 Industries (Frankfurt am Main, Germany). It is a mixture of $\sim 80 \%$ anatase and $\sim 20 \%$ rutile

122 crystals with an average primary particle size of $21 \mathrm{~nm}$ (Ohno et al. 2001; Evonik Industries

123 2007). NM-105 is a standard $\mathrm{nTiO}_{2}$ reference material deposited in the European Commission

124 Joint Research Centre (Rasmussen et al., 2014).

125

126

2.5. $\mathrm{P}-25 \mathrm{nTiO}_{2}$ suspension preparation

127

A known mass of P-25 was added to a known volume of dispersant (autoclaved [Paterson

128

et al. 2011] egg water: distilled water containing sea salt [60 mg/L], pH 7.2 [Westerfield 2000])

129

to produce a $1000 \mu \mathrm{g} / \mathrm{mL}$ stock suspension. The suspension was agitated using a probe sonicator

130 (Hielscher UP400S, Germany) at $320 \mathrm{~W}(0.5$ cycle, amplitude $85 \%)$ in an ice bath for at least 30

$131 \mathrm{~min}$ followed by bath sonication (Elmasonic $\mathrm{S} 100 \mathrm{H}$, Germany) for $15 \mathrm{~min}$. The suspension was

132 used immediately after preparation. Working solutions of other concentrations were prepared by

133 stepwise dilution of stock suspension with egg water. The $\mathrm{Ti}^{4+}$ (ionic portion of $\mathrm{nTiO}_{2}$ ), was also

134 quantified based on Samaee et al. (2015).

135

136 2.6. $\mathrm{nTiO}_{2}$ characterization

137 The characterization was made at two times: 1) immediately after preparation of the $138 \mathrm{nTiO}_{2}$ suspension (before waterborne exposure) and 2) $24 \mathrm{~h}$ after preparation of the $\mathrm{nTiO}_{2}$ 
suspension (after waterborne exposure) (Kim et al. 2014). Suspension samples at both time points were collected from the center of the water column (Clemente et al. 2014) and the undisturbed top layer (Dalai et al. 2012). Samples were analyzed, as described below, at room temperature. Experiments were carried out in triplicate to calculate the standard deviation (Dalai et al., 2012).

nTiO 2 morphology (Zhu et al., 2008) and primary particle diameter were determined by transmission electron microscopy (TEM). Twenty $\mu \mathrm{L}$ of $\mathrm{nTiO}_{2}(100 \mathrm{ppm})$ was pipetted onto carbon-coated copper grids (Formvar carbon coated grid $\mathrm{Cu}$ Mesh 300, EMS, USA) then dried in a laminar flow hood for $24 \mathrm{~h}$. The microscope (Zeiss EM10C, USA) was operated in bright field mode. Specimens were observed with a Bosch camera (Germany) at an accelerating voltage of $100 \mathrm{kV}$. Particle size distribution (PSD) was statistically computed from 107 particles viewed in a series of images using ImageJ software 1.48 (Wayne Rasband, National Institutes of Health, USA [http://imagej.nih.gov/ij]) (Kim et al. 2014; He et al. 2014). The PSD, average hydrodynamic diameter, polydispersity index (PDI), and surface charge (zeta potential) were characterized by dynamic light scattering (DLS) (Zetasizer Nano ZS instrument [Malvern Instruments, Zen $3600, \mathrm{UK}])$. One $\mathrm{mL}$ of $1 \mu \mathrm{g} / \mathrm{mL} \mathrm{nTiO}_{2}$ suspension was analyzed using a refractive index of $\mathrm{nR}=2.5$ (https://refractiveindex.info/?shelf=main\&book=Ti\&page=Johnson) at $25{ }^{\circ} \mathrm{C}$. Egg water without particles was the control. Three independent measurements were taken with 3 readings per time point (at 0 and $24 \mathrm{~h}$ post suspension preparation), each reading consisting of six runs of $10 \mathrm{~s}$ duration (Faria et al. 2014).

The concentration (colloidal stabilities) of the $0.01,10$, and $1000 \mu \mathrm{g} / \mathrm{mL}$ suspensions were estimated by visible spectroscopy using a UV/Vis/Nir Spectrophotometer (lambda 950, PerkinElmer Inc., USA) (Paterson et al. 2011). In brief, $\mathrm{nTiO}_{2}$ standards were prepared as 10, 20, 
162

163

164

165

166

167

168

169

170

171

172

173

174

175

176

177

178 179 (2015).

180

181

182

183

184

33, 50, and 100-fold dilutions of the stock suspension in egg water and re-sonicated for $10 \mathrm{~s}$. The standards were used to generate a linear concentration curve at the wavelength of maximum absorbance $(321 \mathrm{~nm})$ for the Degussa P-25 material suspended in egg water. Sample absorbance was used to estimate its concentration from the standard curve.

Attenuated total reflectance Fourier-transform infrared spectroscopy (ATR-FTIR) characterization of $\mathrm{nTiO}_{2}$ was carried out in the $650-4000 \mathrm{~cm}^{-1}$ range, with a resolution of $4 \mathrm{~cm}^{-1}$ at room temperature using a Nexus 470 FTIR spectrometer (Thermo-Nicolet, USA).

\subsection{Exposure procedure (or protocol)}

A static renewal fish embryo toxicity test was performed with three $\mathrm{nTiO}_{2}$ concentrations (0.01, 10, and $1000 \mu \mathrm{g} / \mathrm{mL}), \mathrm{Ti}^{4+}(0.0001 \mu \mathrm{g} / \mathrm{mL})$, and a negative control (egg water). This concentration range includes 1 ) the $\mathrm{LC}_{50}$ for $96 \mathrm{~h}$ acute fish toxicity and the $\mathrm{EC}_{50}$ in the fish embryo test for 73 chemicals (Lammer et al. 2009), 2) the predicted realistic and high emission environmental concentrations for nano-nTiO 2 in water $(0.0007$ and $0.016 \mu \mathrm{g} / \mathrm{mL}$, respectively) (Mueller and Nowack 2008), and 3) extends both below and above the concentration range of prior studies of zebrafish exposed to water-borne nTiO 2 (Clemente et al. 2014; Wang et al. 2014; Yan et al. 2014). Exposure procedure of embryo-larvae was carried out based on Samaee et al.

Embryo-larvae were exposed to $\mathrm{nTiO}_{2}$ from day 0 (at 4 hpf [the sphere stage of the blastula stage - Yan et al. 2014]) to day 6 (incomplete yolk resorption). This time period normally spans from egg fertilization to the time of hatch and then to yolk resorption of the sac fry following a well characterized set of developmental stages. The embryo-larvae grew on yolk nutrients, and were not fed. 

replaced with egg water for a depuration period of 4 days (see studies of Paterson et al. [2011] on 187 Japanese medaka). From day 6 to day 9 (202 hpe) larvae were fed Paramecium spp. twice daily 188 (Varga 2011). On day 5 to 6 the digestive tract opens and digestive enzymes are secreted, 189 suggesting the larval fish can begin exogenous feeding even though the yolk sac is not yet 190 completely depleted (Holmberg et al. 2004). Culture medium was completely changed after each 191 feeding.

192 Plates were examined at 34, 58, 82, 106, 130, 154, 178, and 202 hpe. These times 193 correspond with known developmental stages: 34 hpe (embryonic stage); 58 hpe (hatching); 82 194 hpe (yolk sac larva/eleutheroembryos [stage between hatching and start of external feed intake] 195 [Oliver et al. 2015]); 106 hpe (gas bladder inflation [Goolish and Okutake 1999], $4 \mathrm{~mm}$ free 196 swimming larva [Chen et al. 2011], and opening of gut end to end [Wilson 2012]); 130 hpe 197 (initiation of exogenous feeding while yolk sac is not yet completely depleted [Holmberg et al. 198 2004]); and 157 hpe (complete depletion of yolk sac [Jardine and Litvak 2003; Wilson 2012]) 199 (Figure 1).

At each time point, the following were recorded: i) HR, ii) mortality rate (dead embryo-

201 larvae were removed), and iii) morphometries of four embryo-larvae specimen (for embryo202 larvae biometry). The exposure solution was completely changed at each time point (Kim et al. 203 2014).

204

205 2.8. Recording of endpoints

206 2.8.1. Morphometric characteristics (MCs) 
Four embryo-larvae specimens were randomly taken at each sampling time from each treatment. They were fixed in 10\% neutral buffered formalin for $24 \mathrm{~h}$ (Vicario-Parés et al. 2014).

Photomicrographs were taken of the fixed specimens (Figure 2) using a stereomicroscope 210 (Zeiss) equipped with a digital camera (Carl Zeiss Inc.). Digital images were processed with 211 Image J 1.48 to quantify embryo-larvae morphometric characteristics (Figure 3).

2.8.2. Calculation of embryo-larvae viability parameters

Viability calculations included the following: 1) Hatching rate, $\mathrm{HR}=($ Hatched embryos 215 Total number of cultured embryos $) \times 100)$ at 58, 82, and $106 \mathrm{hpe}$; and 2$)$ survival rate, $\mathrm{SR}=(\mathrm{Alive}$ 216 larvae/Total number of cultured embryo-larvae) $\times 100)$ at 34, 58, 82, 106, 130, 154, 178, and 202 217 hpe. HR and SR descriptive statistics (mean, standard deviation [SD], and coefficient of variation $218[\mathrm{CV}])$ were calculated. $\mathrm{LC}_{50}$ values and their $95 \%$ confidence intervals for $\mathrm{nTiO}_{2}$ exposurelwere 219 assessed by Probit analysis using SPSS IBM (version 20; SPSS Inc., Chicago, IL, USA).

\subsection{Statistical analysis}

Data normality was tested by the Anderson-Darling method. Univariate analysis of

223 variance (ANOVA; followed by Duncan's multiple range post hoc test) and cluster analysis 224 (followed by multivariate analysis of variance [MANOVA]) were used to test for differences 225 among treatment groups for HR, SR, and MCs. A $p$-value of 0.05 was accepted for statistical 226 significance. Simple regression models were formulated to characterize MCs and the endpoints 227 that are correlated to HR and SR. A $p$-value of $<0.002$ was accepted for determining the level of 228 significance for the regression analysis; considered to be the statistical significance threshold 229 after applying the Bonferroni's adjustment for the critical value of $p<0.05$ to minimize the chance 
230 of type I statistical error. All statistical analyses were performed using IBM SPSS (version 20;

231 SPSS Inc., Chicago, IL, USA), and Excel 2010 (Microsoft Corporation, Redmond, WA, USA).

232

233 3. Results

$234 \quad 3.1 . \mathrm{nTiO}_{2}$ characteristics

235 TEM images of $\mathrm{nTiO}_{2}$ are shown in Figure $4 \mathrm{a}$ and $\mathrm{f}$. The $\mathrm{nTiO}_{2}$ particles were 236 approximately polyhedral with rounded borders with relatively uniform size distribution. Their 237 diameter (mean $[\mathrm{SD}]=22[5] \mathrm{nm})$, was consistent with the manufacturer-reported value $(21 \mathrm{~nm}$; 238 see section 2.4).

The intensity-averaged hydrodynamic diameter distribution of $\mathrm{nTiO}_{2}$ dispersed in egg 240 water is shown in panels $b$ and $g$ of Figure 4. The average particle diameter (Z-average) and PDI 241 of the $\mathrm{nTiO}_{2}$ immediately after preparation of the $\mathrm{nTiO}_{2}$ suspension (Figure 4b), were $197[1] \mathrm{nm}$ 242 and 0.16 [0.01] (mean [SD]) (less than 0.25, indicating that the suspension was monodispersed 243 without significant aggregation [Li et al. 2013]). The parameters $24 \mathrm{~h}$ after preparation were 192 $244[6] \mathrm{nm}$ and $0.15[0.02]$ (mean [SD]) (Figure 4g).

Zeta potential was 34 [1] (mean [SD]) $\mathrm{mV}$ (Figure 4e), immediately after preparation of 246 the $\mathrm{nTiO}_{2}$ suspension and 16[0] (mean [SD]) $\mathrm{mV}$ (Figure 4j), $24 \mathrm{~h}$ after its preparation. The zeta 247 potential was quite high immediately after $\mathrm{nTiO}_{2}$ suspension preparation (Figure 4e) what 248 indicates a low tendency to agglomeration. The decrease of this value $24 \mathrm{~h}$ later (Figure $4 \mathrm{j}$ ) 249 indicates an increased tendency to agglomerate.

Visible spectrophotometry indicated a significant decrease in the concentration of 251 dispersed $\mathrm{nTiO}_{2}$ from 0 to $24 \mathrm{~h}$ after its preparation; the $\mathrm{nTiO}_{2}$ concentration of $500 \mu \mathrm{g} / \mathrm{mL}$ 252 immediately after suspension preparation decreased to $40 \mu \mathrm{g} / \mathrm{mL}$ after $24 \mathrm{~h}$. This is not 
253 surprising, because in suspension, $\mathrm{nTiO}_{2}$ tends to form large particles and most of the 254 agglomerates settle out (Adams et al. 2006). Dr. José M. Navas (Department for the 255 Environment, INIA, Spain) suggested that this does not indicate a change in the $\mathrm{nTiO}_{2}$ 256 concentration in the entire $\mathrm{nTiO}_{2}$ dispersion, but that $\mathrm{nTiO}_{2}$ is not present in the water column 257 (personal communication 2017). Chen et al. (2011) suggest that although sedimentation occurs, 258 the embryo-larvae are constantly exposed to the $\mathrm{nTiO}_{2}$ aggregates during the bioassay because 259 the embryo-larvae are mostly located on the bottom of microplates before they can freely swim.

260 The FTIR spectra of $\mathrm{nTiO}_{2}($ Figure 4k-m) clearly shows two bands. The first, observed at $2613250 \mathrm{~cm}^{-1}$, correspond s to the stretching vibration of the hydroxyl group $(\mathrm{O}-\mathrm{H})$ of the $\mathrm{nTiO} 2$. The 262 second around $1630 \mathrm{~cm}^{-1}$ corresponds to bending modes of water Ti-OH (Nadica et al. 2006; 263 Mugundan et al. 2015; León et al. 2017). The FTIR spectra at 0 (Figure 4k), 12 (Figure 4l), and

$26424 \mathrm{~h}($ Figure $4 \mathrm{~m})$ after $\mathrm{nTiO}_{2}$ suspension preparation are the same, suggesting no modification of 265 the NP surface chemistry in these $24 \mathrm{~h}$. For the results of titanium analysis, see Samaee et al. 266 (2015).

267

268 3.2. Effect of $\mathrm{Ti}^{+4}$ on $\mathrm{HR}, \mathrm{SR}$, and MCs

269 To determine if there was any contribution of the soluble fraction to the $\mathrm{nTiO}_{2}$ response, 270 embryos-larvae were exposed to the $0.0001 \mu \mathrm{g} / \mathrm{mL} \mathrm{Ti}^{+4}$, the concentration of the soluble fraction 271 of $\mathrm{nTiO}_{2}$. No significant difference of $\mathrm{HR}, \mathrm{SR}$, and MC $(>0.05)$ was detected when comparing 272 embryo-larvae exposed to $\mathrm{Ti}^{+4}$ to controls (Table 1). 
$\mathrm{nTiO}_{2}$ had a significant effect on $\mathrm{HR}$ at 58 hpe (Figure 5a), but not 82 hpe (Figure 5b), or

276106 hpe (Figure 5c). Cluster analysis, based on descriptive statistics (mean, SD, and CV) of HR

277 (Figure 5j), categorized the four treatments $\left(0,0.01,10\right.$, and $\left.1000 \mu \mathrm{g} / \mathrm{mL} \mathrm{nTiO}_{2}\right)$ into separate 278 statistical groups. The validity of the statistical groups was verified by MANOVA. There are 9

279 distinct statistical groups in the HR dendrogram (Figure 5j, Roman numerals). Although in some 280 cases there are individuals from the same treatment within different clusters, the majority of the 281 clusters were based on the same treatment and there was clear separation of the endpoints related 282 to the exposure concentration.

\subsection{Differences among treatments concerning SR}

The mortality rate was between $12.3[6.8] \%$ and $7.8[4.8] \%$ (mean $[\mathrm{SD}]$ ) in the $\mathrm{nTiO}_{2}$ exposed embryo-larva and controls, respectively. There was a significant variation among 287 treatments concerning SR at 58 hpe (Figure 5d), 82 hpe (Figure 5e), 106 hpe (Figure 5f), 130288154 hpe (Figure 5g), 178 hpe (Figure 5h), and 202 hpe (Figure 5i). Cluster analysis of SR 289 (Figure 5k) categorized the four $\mathrm{nTiO}_{2}$ treatments into 8 statistically distinct groups in the dendrogram (Figure 5k Roman numerals). We were unable to determine a $\mathrm{LC} 50$ for $\mathrm{nTiO}_{2}$.

\subsection{Relationship between HR and SR}

$294 \mathrm{HR}$ at $106 \mathrm{hpe}$ (the time to hatch of all live embryos [total hatching]). But there was no 295 significant relationship between SR and HR at 34 (the day of onset of hatching only in 1000 $296 \mu \mathrm{g} / \mathrm{mL} \mathrm{nTiO}_{2}$-exposed embryo groups), 58 (the day of onset of hatching in $0,0.01$, and 10 $297 \mu \mathrm{g} / \mathrm{mL} \mathrm{nTiO}_{2}$-exposed embryo groups), and 82 (time to $60 \%$ hatch) hpe. 
3.6. $\mathrm{nTiO}_{2}$-induced morphological responses

We detected a concentration-dependent precipitation of $\mathrm{nTiO}_{2}$ on embryos within $34 \mathrm{~h}$ of

301

302

303

304

305

306

307

308

309

310

311

312

313

314

315

316

317

318

319

320

\subsection{Variation among treatments concerning MCs}

The $\mathrm{nTiO}_{2}$-exposed groups significantly differed from controls for the changes in MCs at 82 hpe (for BL-82, PoPB-82, BL/APB-82, BL/BD2-82, BL/HL-82, APB/PoPB-82, PoPB/BD182, and PoPB/BD2-82 [Table 1, rows 13-14, 16, 18-20, 22-23]). Significant differences were also seen at 106 hpe (for APB-106, BD1-106, BD2-106, BL/PoPB-106, BL/BD1-106, BL/BD2106, APB/PoPB-106, PoPB/BD1-106, PoPB/BD2-106, and BD1/HL-106 [Table 1, rows 25-27, 29-31, 33, 36-38]), 130 hpe (for APB/BD1-130 [Table 1, row 41]), 178 hpe (for PoPB-178, 
BL/BD2-178, PoPB/BD2-178, and BD1/BD2-178 [Table 1, rows 50-51, 54-54]), and 202 hpe (for BL-202, PoPB-202, BL/BD1-202, BL/BD2-202, PoPB/BD1-202, and PoPB/BD2-202 [Table 1, rows 55-60]).

Embryo-larva exposed to $0.01,10$, and $1000 \mu \mathrm{g} / \mathrm{mL}$ significantly differed from each other based on 9 MCs (BD1 at 106 hpe [denoted as BD1-106], BD2-106, BL/APB-106, APB/HL-106, APB-154, HL-154, APB/BD1-178, BD1/HL-202, and BD2/HL-202 [Table 1, rows 26-28, 35, 42-43, 52, 61-62]), 9 (BD2-106, BL/APB-106, BL/HL-106, APB-130, HL-130, APB/BD1-154, BL-178, APB-178, and BD1/BD2-178 [Table 1, rows 27-28, 32, 39-40, 45, 48-49, 54]), and 13 (for BD1-82, BL/PoPB-82, BL/BD2-82, APB/BD1-82, PoPB/BD1-82, PoPB/HL-82, BD2-106, BL/PoPB-106, APB/PoPB-106, APB/BD2-106, BL/BD2-154, PoPB/BD2-154, and BD1/BD2154 [Table 1, rows 15, 17-18, 21-22, 24, 27, 29, 33-34, 44, 46-47]), respectively.

Cluster analysis was performed on $\mathrm{MCs}$ (Figure 51) that categorized the four $\mathrm{nTiO}_{2}$ treatments into separate statistical groups, to create a dendrogram that allows visual examination of the distribution of the four treatment groups. There was a significant separation based on the concentration of $\mathrm{nTiO}_{2}$. There were 9 (Figure 51, the Roman numerals) distinct groups in the dendrograms. Although in some cases there are individuals from the same treatment group within different clusters, the majority of the clusters were based on the same treatment and there was clear separation of the end points that were related to the exposure concentration.

\subsection{Relationship of MCs with HR and SR}

The MCs (as dependent variables) significantly (either negatively [boldface] or positively) correlated to HR (as the independent variable) at 58 (Table 2, rows 1-17), 82 (Table 2, rows 18-25), and 106 (Table 2, rows 26-32) hpe by 32 simple regression models. SR and its 
344 standard deviation (SRSD) (Table 3) at 106 (row 1), 130 (rows 2-12), 178 (rows 13-29), and 202

345 (rows 30-55) hpe were significantly negatively (Table 3, boldface) or positively correlated to

346 MCs (or their ratios) at 82 (Table 3, rows 1, 2, 4, 5, 13, 20, 21, 34, 35, 36-41), 106 (Table 2, rows

$3473,14,42-46$ ), 130 (Table 3, rows 6-12, 22-28), 154 (Table 3, rows 30, 47-51), 178 (Table 3, rows

$34815-19,29,31-33,52$, and 53), and 220 (Table 3, rows 54 and 55) hpe by 55 simple regression 349 models.

\section{Discussion}

Embryo-larvae viability parameters (such as "hatching events" and "survivability" at different embryo/larvae stages) are important endpoints that have been used as criteria (1) to characterize $\mathrm{nTiO}_{2}$-induced general responses in zebrafish (Yeo and Jo,2007; Xu et al. 2012; Kovrižnych et al., 2013; Wang et al., 2014), (2) to evaluate the effects of exposure to $\mathrm{nTiO}_{2}$ on survivability in a disease outbreak (Jovanovic et al., 2015), (3) to characterize toxicity of 357 different $\mathrm{nTiO}_{2}$ formulations (Clemente et al., 2014), (4) to assess effect of light on $\mathrm{nTiO}_{2}$ 358 toxicity (Ma et al., 2013; Clemente et al., 2014), (5) to survey $\mathrm{nTiO}_{2}$ toxicity combined with other chemicals (Yan et al.,2014), (6) to discriminate the toxicity of different forms of $\mathrm{nTiO}_{2}$

360 (ion, particle, and bulk) (Vicario-Parés et al., 2014), and (7) to follow $\mathrm{nTiO}_{2}$ toxicity in offspring 361 (Fouqueray et al., 2013). Embryo-larvae phenotypic characteristics are other most common 362 endpoints that are considered to characterize $\mathrm{nTiO}_{2}$ toxicity in zebrafish embryo-larvae.

In the studies mentioned in the previous paragraph embryo-larvae viability parameters 364 such as "hatchability" and "survivability" (in most studies at a single embryonic/larval stage) and 365 phenotypic responses were considered as independent endpoints to characterize $\mathrm{nTiO}_{2}$-induced 366 toxicity. None of the studies evaluated relationships either among viability parameters (e.g. 
367 between hatching events and survivability) or between viability parameters and other endpoints

368 (e.g. between phenotypic alterations and hatching events or survivability). The experimental 369 design of the above mentioned studies did not enable them to explore such relationships. 370 Evaluation of such relationships needs more endpoints, i.e. a big data set while prior studies used

371 limited endpoints to address their hypotheses. In the earlier studies the phenotypic analyses of $372 \mathrm{nTiO}_{2}$-induced defects was performed based upon morphological characteristics. Generating 373 quantitative data from morphometric characteristics (MC) has been largely ignored or under374 used.

375 In the current study "hatchability", "survivability", and 21 morphometric characteristics 376 (each at multiple times, both during $\mathrm{nTiO}_{2}$ exposure and a depuration period) were determined to 377 characterize $\mathrm{nTiO}_{2}$-induced toxicity in zebrafish embryo-larvae. In fact, 171 sub-lethal (i.e. 378 hatchability at 3 times and 21 morphometric characteristics at 8 time points) and survivability at 3798 times were used to address the hypotheses of this study. The values of the 179 endpoints 380 provided with enough data to define relationships between sub-lethal endpoints (e.g. between 381 hatching events and morphometric alterations) and between sub-lethal and acute endpoints (e.g. 382 between survivability and hatching event or morphometric alterations). To our knowledge the 383 current study is the first in which morphometric alterations have comprehensively been 384 considered to characterize $\mathrm{nTiO}_{2}$-induced toxicity.

386 4.1. $\mathrm{Ti}^{+4}$ concentration

387 In the current study, $\mathrm{Ti}^{+4}$ accounted for less than $0.00001 \%$ of the total titanium content 388 in the $\mathrm{nTiO}_{2}$. This is consistent with reports where the titanium was cited as a low concentration 389 element in aquatic ecosystems (Orians et al. 1990; Croot 2011), artificial solutions (Kumazawa 
et al. 2002; Yamamoto et al. 2004; Zhu et al. 2008; Johnston et al. 2010; Vicario-Parés et al.

391 2014; He et al. 2014), and in the aqueous environment of cells (Kumazawa et al. 2002).

392

4.2. Comparison of $\mathrm{Ti}^{+4}$-treated groups with control

There were no significant differences between $\mathrm{Ti}^{+4}$-treated groups and controls concerning HR, SR, and MC, i.e. $0.0001 \mu \mathrm{g} / \mathrm{mL} \mathrm{Ti}^{+4}$ did not have any effect on embryo-larvae morphometrics and viability (Table 1). This is hypothesized to be attributed to the fact that $0.0001 \mu \mathrm{g} / \mathrm{mL}$ is a relatively low exposure concentration of $\mathrm{Ti}^{+4}$ (Monteith et al. 1993; Liao et al. 1999; Cadosch et al. 2009).

4.3. $\mathrm{nTiO}_{2}$-induced variation in $\mathrm{SR}$ and $\mathrm{HR}$

401

Statistical analyses based on SR descriptive statistics at 58, 82-154, 178, and 202 hpe

402 revealed significant variability among $\mathrm{nTiO}_{2}$-exposed and unexposed embryo-larvae, even at 403 environmentally-relevant concentrations $(0.01 \mu \mathrm{g} / \mathrm{mL}$ [Mueller and Nowack 2008]) but also 404 among the $\mathrm{nTiO}_{2}$-exposed groups. The findings contradict some early studies in which zebrafish 405 embryo-larvae (Zhu et al. 2008; Xu et al. 2012; Kovrižnych et al. 2013; Vicario-Parés et al. 406 2014), medaka (Paterson et al. 2011), and fathead minnow (Jovanović et al. 2011a) have been 407 cited as low sensitive models to $\mathrm{nTiO}_{2}$ acute toxicity.

By day 4 (106 hpe), all individuals had hatched. There was no statistically significant 409 difference between treatment groups concerning HR (Figure 5c). This is contrary to the study of 410 Yan et al. (2014) in which the exposure of embryos to $40 \mathrm{mg} / \mathrm{L}$ of nTiO 2 led to a significantly 411 decreased HR compared to lower concentrations and controls. The different biological responses 412 to $\mathrm{nTiO}_{2}$ exposure observed among studies might be attributed to characteristics of the 
413 nanoparticles (size [Lovern and Klaper 2006], crystal form [Zhu et al. 2009], morphology, 414 chemical composition [Wiesner et al. 2006]), dispersant (e.g., pH [Pettibone et al. 2008; French 415 et al. 2009], ionic strength [Truong et al. 2012]), as well as the exposure protocol (e.g. duration 416 of exposure [Federici et al. 2007]).

417 Hatching began on day 2 (34 hpe). Early hatching (2\% at $34 \mathrm{hpe})$ was only observed in $4181000 \mu \mathrm{g} / \mathrm{mL} \mathrm{nTiO}_{2}$-exposed embryos. There was a significant concentration-dependent $\mathrm{HR}$ 419 difference among $\mathrm{nTiO}_{2}$-exposed and unexposed groups at 58 hpe (Figure 5a). At 82 hpe $>50 \%$ 420 of embryos hatched (Figure 5b) with a concentration-dependent difference among the four 421 treatment groups. The data show a concentration-dependent acceleration in hatching in $\mathrm{nTiO}_{2}-$ 422 exposed treatment groups $(0.01,10$, and $1000 \mu \mathrm{g} / \mathrm{mL})$ compared to control. nTiO 2 -induced changes in hatching time have also been observed in other studies, e.g. in 424 the studies of Kovrižnych et al. (2013), Ma and Diamond (2013), Fouqueray et al. (2013), and 425 Samaee et al. (2015) the effects of $\mathrm{nTiO}_{2}$ on hatching time were reported as accelerated 426 (premature) hatching while in the study of $\mathrm{Xu}$ et al. (2012), the effects were reported as delayed 427 hatching.

428 The above results show a lack of significant difference among treatment groups 429 concerning total hatching while there was significantly variability concerning hatching time. This 430 illustrates that the hatching time is a more sensitive endpoint to characterize $\mathrm{nTiO}_{2}$-induced 431 responses compared to total hatching, consistent with Barton (2002) who suggested the change in 432 hatching time as an important stress response of fish larvae.

434 4.4. Relationship of SR with hatching events 
Many available nanomaterials (e.g. $\mathrm{nTiO}_{2}$ ) do not exhibit a difference in LC50 values

436 between the egg and larvae stage (Kovrižnych et al. 2013), or cause lethal effects unless the 437 concentrations are grossly exaggerated. Thus, the possibility to evaluate hatching events such as 438 hatching time and calculate a concentration that can induce premature or delayed hatching is 439 important (Kovrižnych et al. 2013). Despite the reported effects of $\mathrm{nTiO}_{2}$ on hatching time both 440 in the current study and earlier studies (Xu et al. 2012; Kovrižnych et al. 2013, Ma and Diamond 441 2013, Fouqueray et al. 2013, and Samaee et al. 2015), the relationship of the nTiO 2 -induced 442 change in hatching time and total hatching to embryo-larvae development and survivability in 443 zebrafish has yet to be determined.

As an attempt to address the question in this study, SR at different larval stages (106, $445130,154,178$, and 202 hpe) was found to be significantly correlated to HR at 106 hpe (time to 446 hatch of all live embryos [or total HR]) while the SR was not correlated to the nTiO 2 -induced 447 change in hatching time (HR at 58 [the day of onset of hatching in all treatment groups] and 82 448 [time to $60 \%$ hatch]) hpe. This means that although the magnitude of total hatching can 449 significantly affect embryo-larvae survivability, the $\mathrm{nTiO}_{2}$-induced change in hatching time does 450 not directly affect the survivability.

4.5. $\mathrm{nTiO}_{2}$-induced morphological variation among treatments

We detected a concentration-dependent $\mathrm{nTiO}_{2}$ precipitation on the embryos within $34 \mathrm{~h}$

454 of exposure (Figure 2, panels a-h), consistent with Bai et al. (2010), Paterson et al. (2011), and 455 Yan et al. (2014). When the concentration of $\mathrm{nTiO}_{2}$ was increased to $1000 \mu \mathrm{g} / \mathrm{mL}$ the egg 456 envelope surface became turbid and difficult to observe (Figure 2, panel $\mathrm{g}$ and $\mathrm{h}$ ). Embryos 457 exposed to $\mathrm{nTiO}_{2}$ showed accelerated hatching (Figure 2 panels g-l), compared to controls 
458 (panels a-b) at 34 hpe. For changes in hatching time see Paterson et al. (2011) and references 459 therein.

460 We observed that early hatched embryos had a significantly smaller size (mean [SD] $=$ $4612.12[0.24] \mathrm{mm}$ ) and larger yolk sac relative to body size (a lower TBL to BD-II ratio; mean $462[\mathrm{SD}]=2.83[0.40])($ Figure 2, panels i-1) compared to control (mean $[\mathrm{SD}]=2.87[0.11] \mathrm{mm}$ and 463 mean $[\mathrm{SD}]=4.28[0.29]$, respectively) (Figure 2, panel $\mathrm{m}$ ). This has been reported for medaka 464 (Leung and Bulkley 1979; Paterson et al 2011) and in an earlier study on zebrafish (Samaee et al. 465 2015) following $\mathrm{nTiO}_{2}$ exposure. Such phenotypic alterations have already been discussed by 466 Samaee et al. (2015).

Other observations included bent trunk larvae at 58 hpe (Figure 2, panels 1, n, p-r) and 468 the presence of $\mathrm{nTiO}_{2}$ precipitation on larvae at 58 (Figure 2, panels n-r), 82, 106, and 130 hpe 469 (Figure 2, panels v,z,ad). The bent trunk was the only $\mathrm{nTiO}_{2}$-induced abnormality observed in 470 the current study, consistent with Yan et al. (2014) who reported no significant morphological 471 abnormality in zebrafish embryos exposed to $\mathrm{nTiO}_{2}$ suspensions of different concentrations. In 472 earlier studies other types of $\mathrm{nTiO}_{2}$-induced morphological abnormalities have been reported 473 (Yeo and Kang 2009; Yeo and Kim 2010; He et al. 2014; Wang et al. 2014; Yan et al. 2014). 474 The variations in $\mathrm{nTiO}_{2}$-induced morphological responses observed in different studies can be 475 attributed to the characteristics of the nanoparticles (Lovern and Klaper 2006; Zhu et al. 2009; 476 Wiesner et al. 2006), dispersant (Pettibone et al. 2008; French et al. 2009; Truong et al. 2012), as 477 well as exposure protocol (Federici et al. 2007).

478 The lack of clear morphological differences among $\mathrm{nTiO}_{2}$ treatments at $130,154,178$, 479 and 202 hpe (Figure 2) shows that the morphological changes observed at early larval stages, 34, 48058,82 , and 106 hpe (Figure 2) disappear at advanced developmental stages. Therefore, the 
481 morphological changes observed in the current study could not be considered as potential 482 endpoints (markers) to predict zebrafish embryo-larvae success (survivability).

4.6. $\mathrm{nTiO}_{2}$-induced morphometric variation among treatments

A cluster analysis placed the four $\mathrm{nTiO}_{2}$ treatment groups into separated statistical groups

486 (Figure 51). The analysis revealed that there was significant morphometric variation between

$487 \mathrm{nTiO}_{2}$-exposed and unexposed groups, but also among the exposed groups. These morphometric

488 variabilities reveal the potential of the $\mathrm{MCs}$ to characterize $\mathrm{nTiO}_{2}$-induced responses of embryo489 larvae even at environmentally-relevant concentrations $(0.01 \mu \mathrm{g} / \mathrm{mL}$; Mueller and Nowack 490 2008).

491

492

4.7. Relationship of MCs with HR and SR

493 In the current study morphometric alterations were found to be stable through all 494 zebrafish larval stages, therefore contrary to morphological changes, those that disappeared at 495 advanced larval stages can be nominated as potential endpoints to predict larval success. To 496 evaluate this potential, simple regression models were formulated between MCs and SR. Based 497 on the regression models, MCs significantly correlated to HR, SR, or both. Regarding the 498 significant associations, three groups of MCs were characterized:

The first group of MCs (Tables 2 and 3, non-underlined data) significantly correlated 500 (either positively or negatively [boldface]) to $\mathrm{HR}$ (at 58, 82, and 106 hpe) and SR (during $\mathrm{nTiO}_{2}$ 501 exposure [106 and $130 \mathrm{hpe}$ ] and during depuration [178 and $202 \mathrm{hpe}$ ). The relationship of these 502 MCs with HR at 58, 82, and 106 hpe shows that the morphometric variations are a consequence 503 of the $\mathrm{nTiO}_{2}$-induced changes in hatching time. The synchronous association of the MCs with 
504 both $\mathrm{HR}$ and $\mathrm{SR}$ indicates an indirect effect of the $\mathrm{nTiO}_{2}$-induced change in hatching time on 505 survivability.

506 The second group of MCs significantly correlated to hatchability at 58, 82, and 106 hpe 507 (Table 2, underlined data) but was not significantly associated with SR. This means that the 508 morphometric alterations induced by the change in hatching time do not affect embryo-larvae 509 SR.

The third group of MCs was correlated to SR but not $\mathrm{HR}$ (during $\mathrm{nTiO}_{2}$ exposure [106 511 and $130 \mathrm{hpe}$ ] and during depuration [178 and $202 \mathrm{hpe}$ [Table 3, underlined data]). This shows 512 that the alteration in this group of $\mathrm{MCs}$ cannot be attributed to the $\mathrm{nTiO}_{2}$-induced changes in 513 hatching time. Probably they have appeared either during exposure of developing larvae to $\mathrm{nTiO}_{2}$ 514 (SR at 106 and $130 \mathrm{hpe}$ ) or during depuration (SR at 178 and $202 \mathrm{hpe).}$

On one hand the presented relationships in the three above paragraphs show that two 516 groups of MCs (group 1 [Tables 2 and 3, non-underlined data] and group 3 [Table 3, underlined 517 data]) are significantly correlated to SR. The significant associations of the two groups of MCs 518 with SR clearly highlight the potential of morphometric alterations (as sublethal endpoints) to 519 predict survivability (as an acute end point). On the other hand the synchronous correlation of the 520 group 1 MCs [Tables 2 and 2, non-underlined data] with both HR and SR demonstrates the 521 significant effect of the $\mathrm{nTiO}_{2}$-induced change in hatching time on embryo-larvae survivability 522 (as the one of objectives of the study).

523 In general, a key element complicating the establishment of a link between exposure and 524 a health defect is the time that elapses between exposure and outward response or development 525 of the health defect (Gluckman et al. 2008; Barouki et al. 2012). Thus, it may take years for an 526 individual to present a health defect and in addition may pass on these adverse health effects to 
527 future generations (Jirtle and Skinner 2007). In zebrafish the morphometric alterations appeared 528 within a short period of exposure to different concentrations of $\mathrm{nTiO}_{2}$ (even at environmentally529 relevant concentrations) and could predict later-in-life consequences of an embryonic exposure 530 to $\mathrm{nTiO}_{2}$. Therefore zebrafish can be considered as a potential biological predictor of the acute

531 toxicity of nTiO2. This is contrary to studies in which the embryo-larvae of zebrafish (Zhu et al. 532 2008; Xu et al. 2012; Kovrižnych et al. 2013), medaka (Paterson et al. 2011), and fathead 533 minnow (Jovanović et al. 2011a) have been cited as low sensitive models to nTiO2 acute toxicity 534 based solely on the failure to generate LC50 at environmentally-relevant concentrations. 535

\subsection{Conclusions}

1) In the current study, univariate and multivariate analyses that included HR and SR, as well as $\mathrm{MC}$ values differentiated $\mathrm{nTiO}_{2}$-induced responses (even at environmentally-relevant 539 concentrations) of zebrafish embryo-larvae. 2) Exposure of embryos to $\mathrm{nTiO}_{2}$ led to a significant 540 concentration-dependent change in hatching time (an $\mathrm{nTiO}_{2}$-accelerated [premature] hatching),

541 consistent with previous studies. 3) Total hatching (HR at $106 \mathrm{hpe}$ ) was significantly correlated 542 to SR but there was not a significant relationship between the change in hatching time (HR at 34, 54358 and 82 hpe) and SR. This suggests that the $\mathrm{nTiO}_{2}$-induced change in hatching time does not 544 directly affect embryo-larvae survivability. 4) Larval morphometric alterations were significantly 545 correlated to both $\mathrm{nTiO}_{2}$-induced change in hatching time and total hatching, suggesting that $546 \mathrm{nTiO}_{2}$-induced changes in hatching events can affect embryo-larvae development. 5) Most of the 547 evaluated morphometric variations were significantly correlated to both the change in hatching 548 time and SR. This clearly provides evidence of the indirect effect of the $\mathrm{nTiO}_{2}$-induced change in 549 hatching time on embryo-larvae survivability in zebrafish. 6) The MCs whose variations are 
550 correlated to embryo-larvae SR can be considered as potential endpoints to predict embryo551 larvae survivability in an $\mathrm{nTiO}_{2}$-toxicity test. 7) The above mentioned findings provide evidence 552 of the significant influence of the hatching events, i.e. $\mathrm{nTiO}_{2}$-induced change in hatching time 553 and total hatching, on zebrafish embryo-larvae development and survivability. 8) The results 554 suggest zebrafish can be considered as a potential biological predictor of the acute toxicity of $555 \mathrm{nTiO}_{2}$.

556

557 Acknowledgments

558 The authors are grateful to Prof. Dr. Christopher Joseph Martyniuk (Center for 559 Environmental and Human Toxicology, University of Florida, USA) for his helpful scientific and 560 linguistic comments during preparation of the current manuscript.

561

562 References

563 Adams L, Lyon D, Alvarez P. 2006. Comparative eco-toxicity of nanoscale $\mathrm{TiO}_{2}, \mathrm{SiO}_{2}$, and $\mathrm{ZnO}$ $564 \quad$ water suspensions. Water Res 40:3527-32.

565 Bai W, Zhang Z, Tian W, He X, Ma Y, Zhao Y, Chai Z. 2010. Toxicity of zinc oxide 566 567 568 569

Barouki R, Gluckman PD, Grandjean P, Hanson M, Heindel JJ. 2012. Developmental origins of 571 non-communicable disease: implications for research and public health. Environ Health 572 11:1-9. 
573 Barton BA. 2002. Stress in fishes: A diversity of responses with particular reference to changes in circulating corticosteroids. Integr Comp Biol 42:517-525.

575 Braunbeck T, Böttcher M, Hollert H, Kosmehl T, Lammer E, Leist E, Rudolf M, Seitz N. 2005.

576

577

578

579

580

581

582

583

584

585

586

587

588

589

590

591

592

593

594

Towards an alternative for the acute fish LC50 test in chemical assessment: the fish embryo toxicity test goes multi-species—an update. ALTEX 22:87-102.

Braunbeck T, Lammer E. 2006. Background paper on fish embryo toxicity assays. Germany, Federal Environment Agency (UBA contract number 20385 422), pp 1-298.

Cadosch D, Chan E, Gautschi OP, Filgueira L. 2009. Metal is not inert: Role of metal ions released by biocorrosion in aseptic loosening-Current concepts. $J$ Biomed Mater Res A $91: 1252-1262$.

Chen TH, Lin CY, Tseng MC. 2011. Behavioral effects of titanium dioxide nanoparticles on larval zebrafish (Danio rerio). Mar Pollut Bull 63(5-12):303-8.

Clemente Z, Castro VL, Moura MA, Jonsson CM, Fraceto LF. 2014. Toxicity assessment of $\mathrm{TiO}_{2}$ nanoparticles in zebrafish embryos under different exposure conditions. Aquat Toxicol 147:129-39.

Colvin VL. 2003. The potential environmental impact of engineered nanomaterials. Nature Biotechnol 21:1166-1170.

Croot PL. 2011. Rapid determination of picomolar titanium in seawater with catalytic cathodic stripping voltammetry. Anal Chem 83:6395-6400.

Dalai S, Pakrashi S, Kumar RSS, Chandrasekaran N, Mukherjee A. 2012. A comparative cytotoxicity study of $\mathrm{TiO}_{2}$ nanoparticles under light and dark conditions at low exposure concentrations. Toxicol Res 1:116-130. 
595 Evonik Industries. 2007. Product Information Sheet, Aeroxide ${ }^{\circledR} \mathrm{TiO}_{2} \mathrm{P}-25$ Hydrophilic Fumed Titanium Dioxide. USA, NJ, Parsippany.

597 Faria M, Navas JM, Soares AMVM, Barata C. 2014. Oxidative stress effects of titanium dioxide 598 nanoparticle aggregates in zebrafish embryos. Sci Total Environ 470-471:379-389.

599

600

601

602

603

604

605

606

607

608

609

610

611

612

613

614

615

616

617

Federici G, Shaw BJ, Handy RD 2007. Toxicity of titanium dioxide nanoparticles to rainbow trout (Oncorhynchus mykiss): gill injury, oxidative stress, and other physiological effects. Aquat Tox 84:415-430.

Fouqueray M, Noury P, Dherret L, Chaurand P, Abbaci K, Labille J, Rose J, Garric J. 2013. Exposure of juvenile Danio rerio to aged $\mathrm{TiO}_{2}$ nanomaterial from sunscreen. Environ $\mathrm{Sci}$ Pollut Res Int 20(5):3340-50.

French RA, Jacobsen AR, Kim B, Isley SL, Penn RL, Baveye PC. 2009. Influence of ionic strength, $\mathrm{pH}$, and cation valence on aggregation kinetics of titanium dioxide nanoparticles. Environ Sci Technol 43:1354-1359.

Gluckman PD, Hanson MA, Cooper C, Thornburg KL. 2008. Effect of in utero and early-life conditions on adult health and disease. $N$ Engl J Med 359:61-73.

Goolish EM, Okutake K. 1999. Lack of gas bladder inflation by the larvae of zebrafish in the absence of an air-water interface. $J$ Fish Biol 55:1054-1063.

Griffitt RJ, Hyndman K, Denslow ND, Barber DS. 2009. Comparison of molecular and histological changes in zebrafish gills exposed to metallic nanoparticles. Toxicol Sci 107(2):404-415.

Hall S, Bradley T, Moore JT, Kuykindall T, Minella L. 2009. Acute and chronic toxicity of nano-scale $\mathrm{TiO}_{2}$ particles to freshwater fish, cladocerans, and green algae, and effects of organic and inorganic substrate on $\mathrm{TiO}_{2}$ toxicity. Nanotoxicology 3:91-97. 
618

619

620

621

622

623

624

625

626

627

628

629

630

631

632

633

634

635

636

637

638

He X, Aker WG, Hwang HM. 2014. An in vivo study on the photo-enhanced toxicities of Sdoped $\mathrm{TiO}_{2}$ nanoparticles to zebrafish embryos (Danio rerio) in terms of malformation, mortality, rheotaxis dysfunction, and DNA damage. Nanotoxicology Suppl 1:185-95.

Holmberg A, Schwerte T, Pelster B, Holmgren S. 2004. Ontogeny of the gut motility control system in zebrafish Danio rerio embryos and larvae. J Exp Biol 207:4085-4094.

Jardine D, Litvak MK. 2003. Direct yolk sac volume manipulation of zebrafish embryos and the relationship between offspring size and yolk sac volume. J Fish Biol 63:388-397.

Jirtle RL, Skinner MK. 2007. Environmental epigenomics and disease susceptibility. Nat Rev Genet 8:253-262.

Johnston BD, Scown TM, Moger J, Cumberland SA, Baalousha M, Linge K, van Aerle R, Jarvis K, Lead JR, Tyler CR. 2010. Bioavailability of nanoscale metal oxides, $\mathrm{TiO}_{2}, \mathrm{CeO}_{2}$, and ZnO to fish. Environ Sci Technol 44:1144-1151.

Jovanović B, Anastasova L, Rowe EW, Zhang Y, Clapp AR, Palić D. 2011a. Effects of nanosized titanium dioxide on innate immune system of fathead minnow (Pimephales promelas Rafinesque, 1820). Ecotox Environ Safe 74:675-683.

Jovanović B, Ji T, Palić D. 2011b. Gene expression of zebrafish embryos exposed to titanium dioxide nanoparticles and hydroxylated fullerenes. Ecotoxicol Environ Saf 74:15181525.

Jovanović B, Whitley EM, Kimura K, Crumpton A, Palić D. 2015. Titanium dioxide nanoparticles enhance mortality of fish exposed to bacterial pathogens. Environ Pollut 203:153-164. 
Kim, M.-S, Louis KM, Pedersen JA, Hamers RJ, Petersonad RE, Heideman W. 2014. Using citrate-functionalized $\mathrm{TiO}_{2}$ nanoparticles to study the effect of particle size on zebrafish embryo toxicity. Analyst 139:964-972.

Kovrižnych JA, Sotníková R, Zeljenková D, Rollerová E, Szabová E, Wimmerová S. 2013. Acute toxicity of 31 different nanoparticles to zebrafish (Danio rerio) tested in adulthood and in early life stages - comparative study. Interdiscip Toxicol 6(2):67-73.

Kumazawa R, Watari F, Takashi N, Tanimura Y, Uo M, Totsuka Y. 2002. Effects of Ti ions and particles on neutrophil function and morphology. Biomaterials 23:3757-3764.

Lammer E, Carr GJ, Wendler K, Rawlings JM, Belanger SE, Braunbeck T. 2009. Is the fish embryo toxicity test (FET) with the zebrafish (Danio rerio) a potential alternative for the fish acute toxicity test? Comp Biochem Physiol C 149:196-209.

Lawrence C. 2007. The husbandry of zebrafish (Danio rerio): a review. Aquaculture 269:1-20.

León A, Reuquen P, Garín C, Segura R, Vargas P, Zapata P, Orihuela PA. 2017. FTIR and Raman characterization of $\mathrm{TiO}_{2}$ nanoparticles coated with polyethylene glycol as carrier for 2-methoxyestradiol. Appl Sci 7:49.

Leung T.-y, Bulkley R. 1979. Effects of petroleum hydrocarbons on length of incubation and hatching success in the Japanese Medaka. Bull Environ Contam Toxicol 23:236-243.

Li Y, Zhang W, Niu J, Chen Y. 2013. Surface-coating-dependent dissolution, aggregation, and reactive oxygen species (ROS) generation of silver nanoparticles under different irradiation conditions. Environ Sci Technol 47:10293-10301.

Liao H, Wurtz T, Li J. 1999. Influence of titanium ion on mineral formation and properties of osteoid nodules in rat calvaria cultures. J Biomed Mater Res 47:220-227. 
661 Liu R, Lin S, Rallo R, Zhao Y, Damoiseaux R, Xia T, Lin S, Nel A, Cohen Y. 2012. Automated 662 phenotype recognition for zebrafish embryo based in vivo high throughput toxicity screening of engineered nano-materials. PLoS ONE 7(4):e35014.

664 665 666 667 668 669 670 671

672 673 674 675 676 677 678 679 680 681 682 683

Lovern SB, Klaper R. 2006. Daphnia magna mortality when exposed to titanium dioxide and fullerene (C60) nanoparticles. Environ Toxicol Chem 25:1132-1137.

Ma H, Diamond S. 2013. Phototoxicity of $\mathrm{TiO}_{2}$ nanoparticles to zebrafish (Danio rerio) is dependent on life stage. Environ Toxicol Chemi 32(9):2139-2143.

Menard A, Drobne D, Jemec A. 2011. Ecotoxicity of nanosized $\mathrm{TiO}_{2}$. Review of in vivo data. Environ Pollut 159:677e684.

Metcalfe C, Bennett E, Chappell M, Steevens J, Depledge M, Goss G, Goudey G, Kaczmar S, O’Brien N, Picado A, Ramadan AB. 2009. SMARTEN: strategic management and assessment of risks and toxicity of engineered nanomaterials. In: Linkov I, Steevens J, eds, Nanomaterials: Risks and Benefits. NATO Science for Security and Peace Series C: Environmental Security. The Netherlands, Dordrecht, Springer, pp 95-109.

Monteith MR, Zaharias R, Keller JC. 1993. Effect of soluble Ti on in vitro osteoblast mineralization. J Dent Res 73:400.

Moore MN. 2006. Do nanoparticles present ecotoxicological risks for the health of the aquatic environment? Environ Int 32:967-976.

Mueller NC, Nowack B. 2008. Exposure modeling of engineered nanoparticles in the environment. Environ Sci Technol 42:4447-4453.

Mugundan S, Rajamannan G, Viruthagiri N, Shanmugam R, Gobi P. 2015. Synthesis and characterization of undoped and cobalt-doped $\mathrm{TiO}_{2}$ nanoparticles via sol-gel technique. Appl Nanosci 5:449-456. 
684 Nadica D, Abazovic M, Comor M, Dramicanin D, Jovanovic S, Jovan M. 2006.

685

686

687

688

689

690

691

692

693

694

695

696

697

698

699

700

701

702

703

704

705

Photoluminescence of anatase and rutile $\mathrm{TiO}_{2}$ particles. J Phys Chem B 110:2536625370.

Ohno T, Sarukawa K, Tokeida K, Matsumura M. 2001. Morphology of a $\mathrm{TiO}_{2}$ photocatalyst (Degussa, P-25) consisting of anatase and rutile crystalline phases. J Catal 203:82-86.

Oliver, AL.-S, Muñoz-Olivas R, Landaluze JS, Rainieri S, Cámara C. 2015. Bioaccumulation of ionic titanium and titanium dioxide nanoparticles in zebrafish eleutheroembryos. Nanotoxicology 9(7):835-42.

Orians KJ, Boyle EA, Bruland KW. 1990. Dissolved titanium in the open ocean. Nature $348: 322-325$.

Paterson G, Ataria JM, Hoque ME, Burns DC, Metcalfe CD. 2011. The toxicity of titanium dioxide nanopowder to early life stages of the Japanese medaka (Oryzias latipes). Chemosphere 82:1002-1009.

Pettibone JM, Cwiertny DM, Scherer M, Grassian VH. 2008. Adsorption of organic acids on TiO2 nanoparticles: Effects of $\mathrm{pH}$, nanoparticle size, and nanoparticle aggregation. Langmuir 24:6659-6667.

Rasmussen, K., et al. 2014. Titanium Dioxide, NM-100, NM-101, NM-102, NM-103, NM-104, NM-105: characterization and physico-chemical properties. European Commission. Luxembourg: Publications Office of the European Union. ISBN 978-92-79-38188-1, pp 218.

Samaee S.-M, Rabbani S, Jovanović B, Mohajeri-Tehrani MR, Haghpanah V. 2015. Efficacy of the hatching event in assessing the embryo toxicity of the nano-sized $\mathrm{TiO}_{2}$ particles in 
zebrafish: A comparison between two different classes of hatching-derived variables. Ecotox Environ Safe 116:121-128.

708 Service RF. 2004. Nanotechnology grows up. Science 304:1732-1734.

709 Truong L, Zaikova T, Richman EK, Hutchison JE, Tanguay RL. 2012. Media ionic strength

Varga ZM. 2011. Aquaculture and husbandry at the Zebrafish International Resource Center.

Wiesner MR, Lowry GV, Alvarez P, Dionysiou D, Biswas P. 2006. Assessing the risks of manufactured nanomaterials. Environ Sci 40:4336-4345.

726 Wilson C. 2012. Aspects of larval rearing. ILAR J 53(2):169-178. 
727

728

729

730

731

732

733

734

735

736

737

738

739

740

741

742

743

744

745

746

747

748

749
Xu Z, Zhang Y.-L, Song C, Wu L.-L, Gao H.-W. 2012. Interactions of Hydroxyapatite with proteins and its toxicological effect to zebrafish embryos development. PLoS ONE 7(4):e32818.

Yamamoto A, Honma R, Sumita M, Hanawa T. 2004. Cytotoxicity evaluation of ceramic particles of different sizes and shapes. J Biomed Mater Res 68A:244-256.

Yan J, Lin B, Hu C, Zhang H, Lin Z, Xi Z. 2014. The combined toxicological effects of titanium dioxide nanoparticles and bisphenol A on zebrafish embryos. Nanoscale Res Lett 9:406.

Yeo M.-K, Jo YH. 2007. Bio-toxicity of titanium dioxide nano particles (P-25) in zebrafish development stage. J Environ Toxicol 22(3):189-196.

Yeo M.-K, Kang M. 2009. Effects of CuxTiOy nanometer particles on biological toxicity during zebrafish embryogenesis. Korean J Chem Eng 26:711-718.

Yeo M.-K, Kim H.-E. 2010. Gene expression in zebrafish embryos following exposure to $\mathrm{TiO}_{2}$ nanoparticles. Mol Cell Toxicol 6:97-104.

Zhu RR, Wang SL, Chao J, Shi DL, Zhang R, Sun XY, Yao SD. 2009. Bio-effects of Nano-TiO 2 on DNA and cellular ultrastructure with different polymorph and size. Mater Sci Eng C 29:691-696.

Zhu XS, Zhu L, Duan Z, Qi R, Li Y, Lang YJ. 2008. Comparative toxicity of several metal oxide nano-particle aqueous suspensions to zebrafish (Danio rerio) early developmental stage. Environ Sci Health A 43:278-284. 
756

757

758

759

760

761 TABLES

762 TABLE 1: Comparison of treatment groups $\left(0, \mathrm{Ti}^{+4}, 0.01,10\right.$, and $\left.1000 \mu \mathrm{g} / \mathrm{mL}\right)$ concerning 763 magnitude of $\mathrm{TiO}_{2}$-induced changes in morphometric characteristics.

764 Footnote: Data are mean [SD]. Values superscripted with the same letter are not significantly 765 different, $p<0.05$. See the legend of Figure 3 for abbreviations of the morphometric 766 characteristics (MCs).

767

768 TABLE 2: Simple regression equations, correlation $\left(r^{2}\right), \mathrm{F}$ and $\mathrm{p}$ values of the significant 769 relationships found between the hatching rate (HR; at 58, 82, and $106 \mathrm{hpe}$ ) and the morphometric 770 characteristics (MC; at 82, 106, 130, 154, 178, and 202 hpe). 
771 Footnote: The non-underlined, underlined, and boldface data show MCs that are correlated to

772 both HR and SR, are only correlated to HR, and are negatively correlated to HR and/or SR, 773 respectively. See figure 3 legend for MC abbreviations.

774

775 TABLE 3: Simple regression equations, explanatory effect $\left(r^{2}\right), \mathrm{F}$ and $p$ values of the significant 776 relationships between the mean and standard deviation (SRSD) of survival rate (SR at 106, 130, 777 178, and $202 \mathrm{hpe}$ ) and morphometric characteristics (MC at 82, 106, 130, 154, 178, and 202 778 hpe).

779 Footnote: The non-underlined, underlined, and boldface data show MCs that are correlated to 780 both $\mathrm{HR}$ and $\mathrm{SR}$, are only correlated to SR, and are negatively correlated to HR and/or SR, 781 respectively. See figure 3 legend for MC abbreviations.

782

783

784 FIGURES

785 FIGURE 1: The zebrafish embryo-larvae observation time points.

786

787 FIGURE 2: Photomicrographs of zebrafish embryo-larvae. Images are zebrafish embryo-larvae 788 at $34,58,82,106,130,154,178$, and 202 hpe exposed to 0 (control), $0.01,10$, and $1000 \mu \mathrm{g} / \mathrm{mL}$ $789 \mathrm{nTiO}_{2}$. Scale bar, $1 \mathrm{~mm}$.

790

791 FIGURE 3: Morphometric characteristics determined in zebrafish embryo-larvae. The 792 landmarks on the zebra fish larvae schematics depict the characteristics that were utilized for 793 screening $\mathrm{nTiO}_{2}$-induced responses. TBL (total body length): greatest horizontal body distance 
794

802

803

804

805

806

807

808

809

810

811

812

813

814

815

- anterior-most part of head to the end of body. APB (anterior part of body): anterior-most part of head to the posterior-most insertion of yolk sac. PoPB (posterior part of body): the posteriormost insertion of yolk sac to the end of body. HL (head length): anterior-most part of head to the place where the head is connected to the body. BD-I (body depth I): vertical distance from posterior-most insertion of yolk sac to upper surface of body. BD-II (body depth II): greatest vertical body distance. Fifteen ratios were calculated from the six morphometric characteristics TBL/APB, TBL/PoPB, TBL/BD-I, TBL/BD-II, TBL/HL, APB/PoPB, APB/BD-I, APB/BD-I, APB/HL, PoPB/BD-I, PoPB/BD-II, PoPB/HL, BD-I/BD-II, BD-I/HL, and BD-II/HL.

FIGURE 4: Physicochemical characteristics of $\mathrm{nTiO}_{2}$ particles. (a,f) TEM micrographs for $\mathrm{nTiO}_{2}$ nanoparticles dispersed in test solution (egg water) immediately after suspension preparation (a) and after $24 \mathrm{~h}(\mathrm{f})$. (b-e, g-j) $\mathrm{nTiO}_{2}$ particle size at times representing exposure conditions immediately after suspension preparation (b-d), and 24 h later (g-i). (e, j) Z-potentials of $\mathrm{nTiO}_{2}$ in egg water. ATR-FTIR spectra for $\mathrm{nTiO}_{2}$ immed iately after preparation of suspension (k), and after $12(\mathrm{l})$ and $24 \mathrm{~h}(\mathrm{~m})$.

FIGURE 5: Variation among treatment groups concerning hatching rate (HR) (a-c), survival rate (SR) (d-i),. (a-c) The dendrograms (j-l) illustrate significant differences among zebrafish embryo-larvae exposed to $0,0.01,10$, and $1000 \mu \mathrm{g} / \mathrm{mL} \mathrm{nTiO}_{2}$ for $\mathrm{HR}(\mathrm{j}), \mathrm{SR}(\mathrm{k})$, and MCs (l). The Roman numerals show the number of created groups by cluster analysis. Scatter plots show significant relationships between SR at different developmental stages (as dependent variables) and HR at 106 hpe (as the ind ependent variable) (m-p). 


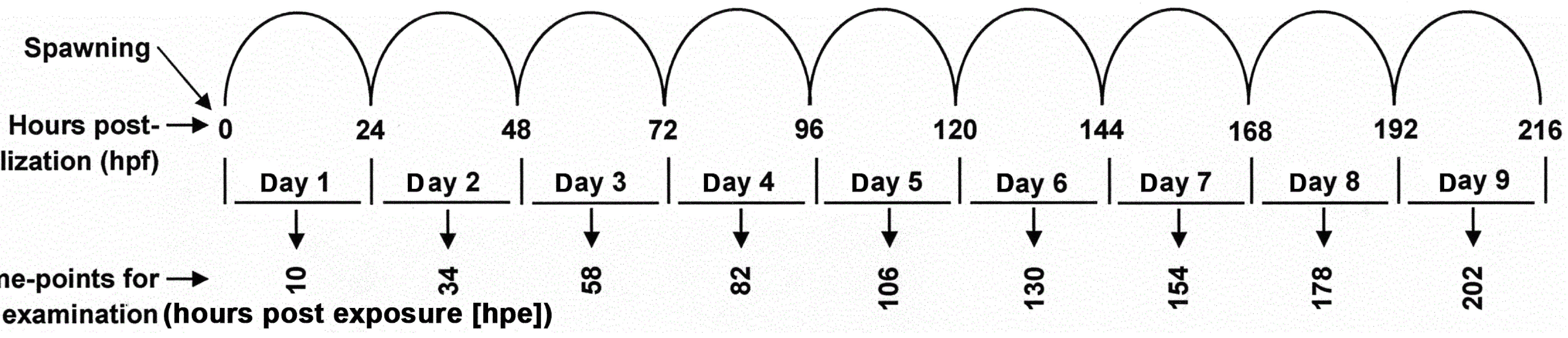


Table 1.

\begin{tabular}{|c|c|c|c|c|c|c|}
\hline \multirow[t]{2}{*}{ No. } & \multirow[t]{2}{*}{ Variables } & \multicolumn{5}{|c|}{$\mathrm{Ti}^{4+}$ and $\mathrm{nTiO}_{2}$ exposure concentration $(\mu \mathrm{g} / \mathrm{mL})$} \\
\hline & & $\mathbf{0}(\mathrm{n}=100)$ & $\begin{array}{c}\mathbf{T i}^{\mathbf{4}^{+}} \mathbf{0} \mathbf{0 . 0 0 0 1} \\
(\mathrm{n}=100)\end{array}$ & $\mathbf{0 . 0 1}(n=100)$ & $10(n=100)$ & $1000(n=100)$ \\
\hline 1 & HR-34 & $0.00[0.00]^{(a)}$ & $0.00[0.00]^{(a)}$ & $0.00[0.00]^{\text {(a) }}$ & $0.00[0.00]^{\text {(a) }}$ & $2.00[6.30]^{(0)}$ \\
\hline 2 & HR-58 & $6.00[9.70]^{(\mathbf{a})}$ & $1.43[3.78]^{(\mathbf{a})}$ & $9.00[19.10]^{(a)}$ & $21.00[29.20]^{(\mathbf{b})}$ & $73.00[17.00]^{(\mathbf{c})}$ \\
\hline 3 & HR-82 & $61.00[29.20]^{(a)}$ & $63.33[19.66]^{(a)}$ & $64.00[29.10]^{(\mathbf{a})}$ & $67.00[37.10]^{(\mathbf{a})}$ & $85.00[14.30]^{(\mathbf{b})}$ \\
\hline 4 & HR-106 & $89.00[9.90]^{(\mathbf{a})}$ & $90.00[14.14]^{(a)}$ & $83.00[16.40]^{(\mathbf{a})}$ & $90.00[19.40]^{(\mathbf{a})}$ & $90.00[12.50]^{(\mathbf{a})}$ \\
\hline 5 & SR-34 & $100.00[0.00]^{(a)}$ & $100.00[0.00]^{(\mathbf{a})}$ & $100.00[0.00]^{(\mathbf{a})}$ & $100.00[0.00]^{(\mathbf{a})}$ & $100.00[0.00]^{(\mathbf{a})}$ \\
\hline 6 & SR-58 & $92.34[2.39]^{(\mathbf{a})}$ & $92.86[1.78]^{(\mathbf{a})}$ & $100.00[0.00]^{(\mathbf{c})}$ & $100.00[0.00]^{(\mathbf{c})}$ & $97.00[2.58]^{(\mathbf{b})}$ \\
\hline 7 & SR-82 & $92.34[2.39]^{(\mathbf{a})}$ & $92.86[1.78]^{(\mathrm{a})}$ & $97.69[1.59]^{(b)}$ & $92.67[3.26]^{(a)}$ & $92.99[3.12]^{(a)}$ \\
\hline 8 & SR-106 & $92.34[2.39]^{(\mathbf{c})}$ & $92.86[1.78]^{(\mathbf{c})}$ & $97.69[1.59]^{(\mathrm{d})}$ & $86.68[3.93]^{(\mathbf{b})}$ & $81.01[4.53]^{(a)}$ \\
\hline 9 & SR-130 & $92.34[2.39]^{(\mathbf{c})}$ & $92.86[1.78]^{(\mathbf{c})}$ & $91.69[5.27]^{(\mathbf{c})}$ & $86.68[3.93]^{(\mathbf{b})}$ & $81.01[4.53]^{(\mathrm{a})}$ \\
\hline 10 & SR-154 & $92.34[2.39]^{(\mathbf{c})}$ & $92.86[1.78]^{(\mathbf{c})}$ & $91.69[5.27]^{(\mathbf{c})}$ & $86.68[3.93]^{(\mathbf{b})}$ & $81.01[4.53]^{(\mathrm{a})}$ \\
\hline 11 & SR-178 & $91.18[2.22]^{(\mathbf{c})}$ & $91.86[2.13]^{(\mathbf{c})}$ & $91.69[5.27]^{(\mathbf{c})}$ & $86.68[3.93]^{(\mathbf{b})}$ & $81.01[4.53]^{(a)}$ \\
\hline 12 & SR-220 & $83.50[4.81]^{(\mathbf{c})}$ & $63.00[1.71]^{(\mathrm{c})}$ & $63.17[1.82]^{(\mathbf{b})}$ & $60.33[6.97]^{(a b)}$ & $57.17[2.50]^{(a)}$ \\
\hline 13 & BL-82 & $2.87[0.22]^{(\mathbf{a})}$ & $2.92[0.24]^{(\mathbf{a})}$ & $3.30[0.12]^{(\mathbf{b})}$ & $3.20[0.14]^{(\mathbf{b})}$ & $3.13[0.22]^{(\mathbf{b})}$ \\
\hline 14 & PoPB-82 & $1.74[0.19]^{(\mathbf{a})}$ & $1.78[0.21]^{(\mathrm{a})}$ & $2.07[0.09]^{(\mathbf{b})}$ & $2.03[0.11]^{(\mathbf{b})}$ & $2.21[0.32]^{(\mathbf{b})}$ \\
\hline 15 & BD1-82 & $0.38[0.00]^{(\mathbf{b})}$ & $0.38[0.00]^{(\mathbf{b})}$ & $0.40[0.02]^{(\mathbf{b})}$ & $0.40[0.01]^{(\mathbf{b})}$ & $0.36[0.04]^{(a)}$ \\
\hline 16 & BL/APB-82 & $2.53[0.13]^{(\mathbf{a})}$ & $2.56[0.14]^{(a)}$ & $2.69[0.08]^{(\mathbf{b})}$ & $2.74[0.07]^{(\mathbf{b})}$ & $2.66[0.04]^{(\mathbf{b})}$ \\
\hline 17 & BL/PoPB-82 & $1.66[0.06]^{(\mathbf{b})}$ & $1.64[0.05]^{(\mathbf{b})}$ & $1.59[0.03]^{(\mathbf{b})}$ & $1.58[0.02]^{(\mathbf{b})}$ & $1.46[0.19]^{(a)}$ \\
\hline 18 & $\mathrm{BL} / \mathrm{BD} 2-82$ & $4.25[0.38]^{(a)}$ & $4.33[0.42]^{(a)}$ & $5.51[0.45]^{(\mathbf{c})}$ & $5.48[0.30]^{(\mathbf{c})}$ & $4.93[0.94]^{(\mathbf{b})}$ \\
\hline 19 & BL/HL-82 & $3.95[0.05]^{(\mathrm{a})}$ & $3.97[0.06]^{(a)}$ & $4.14[0.14]^{(\mathbf{b})}$ & $4.14[0.14]^{(\mathbf{b})}$ & $4.26[0.10]^{(\mathbf{b})}$ \\
\hline 20 & APB/PoPB-82 & $0.66[0.06]^{(\mathbf{b})}$ & $0.65[0.06]^{(\mathbf{b})}$ & $0.59[0.03]^{(\mathbf{a})}$ & $0.58[0.02]^{(\mathbf{a})}$ & $0.55[0.07]^{(a)}$ \\
\hline 21 & APB/BD1-82 & $2.95[0.07]^{(a)}$ & $2.97[0.07]^{(a)}$ & $3.10[0.28]^{(\mathbf{a})}$ & $2.92[0.15]^{(\mathbf{a})}$ & $3.34[0.24]^{(\mathbf{b})}$ \\
\hline 22 & PoPB/BD1-82 & $4.54[0.48]^{(\mathrm{a})}$ & $4.65[0.52]^{(a)}$ & $5.22[0.45]^{(\mathbf{b})}$ & $5.09[0.40]^{(\mathbf{b})}$ & $6.19[0.46]^{(\mathbf{c})}$ \\
\hline 23 & $\mathrm{PoPB} / \mathrm{BD} 2-82$ & $2.58[0.31]^{(a)}$ & $2.65[0.34]^{(a)}$ & $3.46[0.30]^{(\mathbf{b})}$ & $3.48[0.23]^{(\mathbf{b})}$ & $3.46[0.71]^{(\mathbf{b})}$ \\
\hline 24 & PoPB/HL-82 & $2.38[0.11]^{(\mathbf{a})}$ & $2.41[0.12]^{(a)}$ & $2.60[0.12]^{(a b)}$ & $2.69[0.14]^{(\mathbf{b})}$ & $3.02[0.47]^{(\mathbf{c})}$ \\
\hline 25 & APB-106 & $1.37[0.08]^{(\mathbf{b})}$ & $1.39[0.09]^{(\mathbf{b})}$ & $1.26[0.05]^{(\mathbf{a})}$ & $1.28[0.06]^{(a)}$ & $1.30[0.06]^{(\mathrm{a})}$ \\
\hline 26 & BD1-106 & $0.40[0.01]^{(\mathbf{c})}$ & $0.40[0.01]^{(\mathbf{c})}$ & $0.38[0.02]^{(\mathbf{b})}$ & $0.36[0.01]^{(\mathbf{a})}$ & $0.35[0.01]^{(a)}$ \\
\hline 27 & BD2-106 & $0.63[0.00]^{(\mathbf{d})}$ & $0.63[0.00]^{(d)}$ & $0.60[0.02]^{(\mathbf{c})}$ & $0.58[0.01]^{(\mathbf{b})}$ & $0.56[0.03]^{(a)}$ \\
\hline 28 & BL/APB-106 & $2.45[0.12]^{(\mathbf{a b})}$ & $2.43[0.13]^{(a)}$ & $2.70[0.06]^{(\mathbf{c})}$ & $2.62[0.04]^{(\mathbf{c})}$ & $2.53[0.10]^{(\mathbf{b})}$ \\
\hline 29 & BL/PoPB-106 & $1.70[0.06]^{(\mathbf{b c})}$ & $1.71[0.06]^{(\mathbf{c})}$ & $1.59[0.02]^{(\mathrm{a})}$ & $1.62[0.02]^{(\mathbf{a})}$ & $1.66[0.04]^{(\mathbf{b})}$ \\
\hline 30 & BL/BD1-106 & $8.42[0.22]^{(\mathbf{a})}$ & $8.46[0.24]^{(a)}$ & $8.91[0.80]^{(\mathbf{b})}$ & $9.31[0.23]^{(\mathbf{c})}$ & $9.28[0.10]^{(\mathbf{b c})}$ \\
\hline 31 & $\mathrm{BL} / \mathrm{BD} 2-106$ & $5.32[0.02]^{(a)}$ & $5.32[0.02]^{(a)}$ & $5.64[0.42]^{(\mathbf{b})}$ & $5.75[0.27]^{(\mathbf{b c})}$ & $5.93[0.33]^{(\mathrm{c})}$ \\
\hline 32 & BL/HL-106 & $3.99[0.08]^{(\mathbf{a})}$ & $3.97[0.08]^{(a)}$ & $3.96[0.30]^{(\mathbf{a})}$ & $4.17[0.1] 8^{(\mathbf{b})}$ & $3.96[0.12]^{(a)}$ \\
\hline 33 & APB/PoPB-106 & $0.70[0.06]^{(\mathbf{b c})}$ & $0.71[0.06]^{(\mathbf{c})}$ & $0.59[0.02]^{(\mathbf{a})}$ & $0.62[0.02]^{(a)}$ & $0.66[0.04]^{(\mathbf{b})}$ \\
\hline 34 & $\mathrm{APB} / \mathrm{BD} 2-106$ & $2.18[0.12]^{(\mathbf{a})}$ & $2.21[0.13]^{(a)}$ & $2.08[0.13]^{(a)}$ & $2.20[0.13]^{(\mathbf{a})}$ & $2.36[0.18]^{(\mathbf{b})}$ \\
\hline 35 & APB/HL-106 & $1.63[0.05]^{(\mathbf{b})}$ & $1.64[0.06]^{(\mathbf{b})}$ & $1.46[0.09]^{(a)}$ & $1.59[0.05]^{(\mathbf{b})}$ & $1.57[0.10]^{(\mathbf{b})}$ \\
\hline 36 & PoPB/BD1-106 & $4.95[0.04]^{(a)}$ & $4.94[0.05]^{(a)}$ & $5.61[0.52]^{(\mathbf{b})}$ & $5.75[0.10]^{(\mathbf{b})}$ & $5.59[0.11]^{(\mathbf{b})}$ \\
\hline 37 & PoPB/BD2-106 & $3.14[0.10]^{(a)}$ & $3.11[0.11]^{(\mathrm{a})}$ & $3.56[0.29]^{(\mathbf{b})}$ & $3.55[0.15]^{(\mathbf{b})}$ & $3.58[0.21]^{(\mathbf{b})}$ \\
\hline 38 & BD1/HL-106 & $0.48[0.02]^{(a)}$ & $0.47[0.02]^{(a)}$ & $0.45[0.02]^{(\mathbf{b})}$ & $0.45[0.03]^{(\mathbf{b})}$ & $0.43[0.01]^{(\mathbf{b})}$ \\
\hline 39 & APB- 130 & $1.25[0.05]^{(\mathrm{a})}$ & $1.27[0.06]^{(a b)}$ & $1.31[0.05]^{(a b)}$ & $1.39[0.07]^{(\mathbf{c})}$ & $1.32[0.08]^{(\mathbf{b})}$ \\
\hline 40 & HL-130 & $0.83[0.03]^{(\mathbf{a})}$ & $0.84[0.04]^{(\mathrm{a})}$ & $0.84[0.07]^{(\mathbf{a})}$ & $0.90[0.03]^{(\mathbf{b})}$ & $0.85[0.05]^{(a)}$ \\
\hline 41 & $\mathrm{APB} / \mathrm{BD} 1-130$ & $3.31[0.18]^{(\mathbf{a})}$ & $3.34[0.19]^{(a)}$ & $3.58[0.28]^{(\mathbf{b})}$ & $3.75[0.14]^{(\mathbf{b})}$ & $3.58[0.29]^{(\mathbf{b})}$ \\
\hline 42 & APB- 154 & $1.32[0.02]^{(\mathbf{b})}$ & $1.32[0.02]^{(\mathbf{b})}$ & $1.23[0.08]^{(\mathbf{a})}$ & $1.35[0.08]^{(\mathbf{b})}$ & $1.31[0.08]^{(\mathbf{b})}$ \\
\hline 43 & HL-154 & $0.89[0.02]^{(\mathbf{b})}$ & $0.89[0.03]^{(\mathbf{b})}$ & $0.85[0.03]^{(\mathbf{a})}$ & $0.88[0.04]^{(\mathbf{b})}$ & $0.89[0.02]^{(\mathbf{b})}$ \\
\hline 44 & BL/BD2-154 & $7.12[0.53]^{(\mathbf{b})}$ & $7.22[0.58]^{(\mathbf{b})}$ & $7.10[0.35]^{(\mathbf{b})}$ & $7.09[0.43]^{(\mathbf{b})}$ & $6.39[0.47]^{(\mathbf{a})}$ \\
\hline 45 & APB/BD1-154 & $3.94[0.23]^{(\mathbf{a b})}$ & $3.98[0.25]^{(\mathbf{a b})}$ & $3.83[0.10]^{(a)}$ & $4.15[0.37]^{(\mathbf{b})}$ & $3.92[0.12]^{(a b)}$ \\
\hline 46 & PoPB/BD2-154 & $4.57[0.40]^{(\mathbf{b})}$ & $4.65[0.43]^{(\mathbf{b})}$ & $4.64[0.26]^{(\mathbf{b})}$ & $4.44[0.39]^{(\mathbf{b})}$ & $4.01[0.41]^{(\mathrm{a})}$ \\
\hline 47 & $\mathrm{BD} 1 / \mathrm{BD} 2-154$ & $0.65[0.01]^{(\mathbf{b})}$ & $0.65[0.01]^{(\mathbf{b})}$ & $0.64[0.01]^{(\mathbf{b})}$ & $0.64[0.03]^{(\mathbf{b})}$ & $0.61[0.04]^{(a)}$ \\
\hline 48 & BL-178 & $3.85[0.12]^{(\mathbf{b})}$ & $3.83[0.13]^{(\mathbf{b})}$ & $3.73[0.10]^{(\mathbf{b})}$ & $3.53[0.31]^{(\mathbf{a})}$ & $3.70[0.03]^{(\mathbf{b})}$ \\
\hline 49 & APB-178 & $1.31[0.02]^{(\mathbf{b})}$ & $1.31[0.02]^{(\mathbf{b})}$ & $1.32[0.05]^{(\mathbf{b})}$ & $1.20[0.13]^{(\mathbf{a})}$ & $1.28[0.02]^{(\mathbf{b})}$ \\
\hline 50 & PoPB-178 & $2.54[0.10]^{(c)}$ & $2.52[0.11]^{(\mathbf{b c})}$ & $2.41[0.06]^{(\mathbf{a b})}$ & $2.33[0.20]^{(\mathbf{a})}$ & $2.42[0.03]^{(\mathbf{a b c})}$ \\
\hline 51 & BL/BD2-178 & $7.91[0.09]^{(\mathbf{b})}$ & $7.89[0.09]^{(\mathbf{b})}$ & $7.47[0.26]^{(\mathbf{a})}$ & $7.45[0.15]^{(\mathbf{a})}$ & $7.33[0.11]^{(\mathrm{a})}$ \\
\hline 52 & $\mathrm{APB} / \mathrm{BD} 1-178$ & $4.00[0.03]^{(\mathbf{a})}$ & $4.01[0.04]^{(\mathrm{a})}$ & $4.17[0.21]^{(\mathbf{b})}$ & $3.87[0.26]^{(a)}$ & $3.94[0.10]^{(a)}$ \\
\hline 53 & PoPB/BD2-178 & $5.21[0.11]^{(\mathbf{b})}$ & $5.19[0.11]^{(\mathbf{b})}$ & $4.83[0.17]^{(a)}$ & $4.92[0.15]^{(\mathbf{a})}$ & $4.79[0.09]^{(a)}$ \\
\hline 54 & BD1/BD2-178 & $0.67[0.00]^{(\mathbf{c})}$ & $0.67[0.00]^{(\mathrm{c})}$ & $0.64[0.01]^{(\mathbf{a})}$ & $0.65[0.02]^{(\mathbf{b})}$ & $0.64[0.01]^{(a)}$ \\
\hline 55 & BL-202 & $3.89[0.06]^{(\mathbf{b})}$ & $3.88[0.06]^{(\mathbf{b})}$ & $3.71[0.10]^{(\mathbf{a})}$ & $3.62[0.15]^{(\mathbf{a})}$ & $3.64[0.15]^{(a)}$ \\
\hline 56 & PoPB-202 & $2.56[0.05]^{(\mathbf{b})}$ & $2.55[0.05]^{(\mathbf{b})}$ & $2.43[0.12]^{(\mathbf{a})}$ & $2.36[0.12]^{(\mathbf{a})}$ & $2.38[0.08]^{(a)}$ \\
\hline 57 & $\mathrm{BL} / \mathrm{BD} 1-202$ & $12.49[0.15]^{(\mathbf{b})}$ & $12.47[0.16]^{(\mathbf{b})}$ & $11.63[0.19]^{(\mathrm{a})}$ & $11.86[0.64]^{(\mathrm{a})}$ & $11.98[0.75]^{(\mathrm{a})}$ \\
\hline 58 & $\mathrm{BL} / \mathrm{BD} 2-202$ & $7.99[0.14]^{(6)}$ & $7.96[0.16]^{(\mathbf{b})}$ & $7.42[0.35]^{(\mathrm{a})}$ & $7.35[0.29]^{(\mathrm{a})}$ & $7.54[0.48]^{(\mathbf{a})}$ \\
\hline 59 & PoPB/BD1-202 & $8.23[0.13]^{(\mathbf{b})}$ & $8.21[0.14]^{(\mathbf{b})}$ & $7.61[0.29]^{(\mathbf{a})}$ & $7.73[0.34]^{(\mathbf{a})}$ & $7.85[0.55]^{(a)}$ \\
\hline 60 & PoPB/BD2-202 & $5.26[0.11]^{(\mathbf{b})}$ & $5.24[0.12]^{(\mathbf{b})}$ & $4.86[0.33]^{(\mathbf{a})}$ & $4.79[0.17]^{(\mathbf{a})}$ & $4.94[0.34]^{(a)}$ \\
\hline 61 & BD1/HL-202 & $0.37[0.01]^{(\mathrm{a})}$ & $0.37[0.01]^{(\mathrm{a})}$ & $0.39[0.02]^{(\mathbf{b})}$ & $0.36[0.02]^{(\mathbf{a})}$ & $0.36[0.02]^{(a)}$ \\
\hline 62 & BD2/HL-202 & $0.58[0.02]^{(\mathrm{a})}$ & $0.58[0.02]^{(\mathrm{a})}$ & $0.61[0.01]^{(\mathbf{b})}$ & $0.58[0.03]^{(\mathbf{a})}$ & $0.58[0.04]^{(\mathrm{a})}$ \\
\hline
\end{tabular}


Table 2. Table 2. Simple regression equations, correlation $\left(r^{2}\right), F$ and $p$ values of the significant relationships found between the hatching rate (at 58, 82, and $106 \mathrm{~h}$ postexposure) and the morphometric characteristics (at 82, 106, 130, 154, 178, and $202 \mathrm{~h}$ postexposure)

\begin{tabular}{|c|c|c|c|c|c|c|}
\hline \multirow[t]{2}{*}{ No. } & \multicolumn{2}{|l|}{ Variables } & \multirow[b]{2}{*}{ Equations } & \multirow[t]{2}{*}{$r^{2}$} & \multirow[t]{2}{*}{$\mathbf{F}$} & \multirow[t]{2}{*}{$p$} \\
\hline & Independent & Dependent & & & & \\
\hline 1 & HR-58 & PoPB-82 & $y=0.004 x+1.908$ & 0.229 & 11.288 & 0.002 \\
\hline 2 & HR-58 & BD1-82 & $y=-0.001 x+0.398$ & 0.298 & 16.120 & 0.001 \\
\hline 3 & HR-58 & BL/PoPB-82 & $y=-0.003 x+1.635$ & 0.352 & 20.652 & 0.001 \\
\hline 4 & HR-58 & BL/BD1-82 & $y=0.013 x+7.853$ & 0.232 & 11.457 & 0.002 \\
\hline 5 & HR-58 & APB/PoPB-82 & $y=-0.001 x+0.623$ & 0.263 & 13.568 & 0.001 \\
\hline 6 & HR-58 & APB/BD1-82 & $y=0.005 x+2.964$ & 0.267 & 13.837 & 0.001 \\
\hline 7 & HR-58 & PoPB/BD1-82 & $y=0.019 x+4.801$ & 0.536 & 43.942 & 0.001 \\
\hline 8 & HR-58 & PoPB/HL-82 & $y=0.008 x+2.485$ & 0.428 & 28.456 & 0.001 \\
\hline 9 & HR-58 & BD1-106 & $y=0.000 x+0.386$ & 0.390 & 24.287 & 0.001 \\
\hline 10 & HR-58 & BD2-106 & $y=-0.001 x+0.613$ & 0.479 & 34.902 & 0.001 \\
\hline 11 & HR-58 & BD1/HL-106 & $y=0.000 x+0.460$ & 0.219 & 10.626 & 0.002 \\
\hline 12 & HR-58 & BD2/HL-106 & $y=-0.001 x+0.732$ & 0.233 & 11.520 & 0.002 \\
\hline 13 & HR-58 & APB/BD2-106 & $y=0.003 x+2.131$ & 0.279 & 14.691 & 0.001 \\
\hline 14 & HR-58 & BL/BD2-154 & $y=-0.011 x+7.185$ & 0.335 & 19.183 & 0.001 \\
\hline 15 & HR-58 & BD1/BD2-154 & $y=0.000 x+0.647$ & 0.225 & 11.024 & 0.002 \\
\hline 16 & HR-58 & PoPB/BD2-154 & $y=-0.008 x+4.622$ & 0.314 & 17.384 & 0.001 \\
\hline 17 & HR-58 & BL/BD2-178 & $y=-0.005 x+7.663$ & 0.293 & 15.727 & 0.001 \\
\hline 18 & HR-82 & BD 1-82 & $y=-0.001 x+0.449$ & 0.200 & 9.473 & 0.001 \\
\hline 19 & HR-82 & PoPB/BD1-82 & $y=0.033 x+3.078$ & 0.328 & 18.531 & $<0.001$ \\
\hline 20 & HR-82 & PoPB/HL-82 & $y=0.014 x+1.750$ & 0.280 & 14.800 & $<0.001$ \\
\hline 21 & HR-82 & BD1-106 & $y=-0.001 x+0.426$ & 0.220 & 10.715 & 0.002 \\
\hline 22 & HR-82 & BD2-106 & $y=-0.001 x+0.686$ & 0.290 & 15.491 & $<0.001$ \\
\hline 23 & HR-82 & BL/BD2-154 & $y=-0.020 x+8.271$ & 0.239 & 11.965 & 0.001 \\
\hline 24 & HR-82 & APB/BD2-154 & $y=-0.006 x+2.932$ & 0.289 & 15.474 & $<0.001$ \\
\hline 25 & HR-82 & BL/BD2-178 & $y=-0.010 x+8.219$ & 0.234 & 11.617 & 0.002 \\
\hline 26 & HR-106 & PoPB/HL-130 & $y=1.022 x+0.019$ & 0.221 & 10.772 & 0.002 \\
\hline 27 & HR-106 & APB/BD1-178 & $y=-0.022 x+5.986$ & 0.250 & 12.689 & 0.001 \\
\hline 28 & HR-106 & BD1/BD2-178 & $y=0.466 x+0.002$ & 0.266 & 13.792 & 0.001 \\
\hline 29 & HR-106 & BL/BD1-202 & $y=0.065 x+6.171$ & 0.258 & 13.202 & 0.001 \\
\hline 30 & HR-106 & BL/BD2-202 & $y=0.048 x+3.350$ & 0.274 & 14.315 & 0.001 \\
\hline 31 & HR-106 & $\mathrm{PoPB} / \mathrm{BD} 1-202$ & $y=0.051 x+3.354$ & 0.298 & 16.124 & $<0.001$ \\
\hline 32 & HR-106 & $\mathrm{PoPB} / \mathrm{BD} 2-202$ & $y=0.036 x+1.774$ & 0.277 & 14.589 & $<0.001$ \\
\hline
\end{tabular}

Rows $1-12,14-17,19-28$, rows $13,18,29-32$, and rows $2-3,5,10,12,14,16-18,21-27$ show morphometric characteristics that are correlated to both hatching rate (HR) and survival rate (SR), are only correlated to HR, and are negatively correlated to HR, respectively. $\mathrm{APB}=$ anterior part of body; BD-I/BD-II = body depths I and II; BL = body length; HL = head length; PoPB = posterior part of body. 
Table 3. Table 3. Simple regression equations, explanatory effect $\left(r^{2}\right), F$ and $p$ values of the significant relationships between the mean and standard deviation of survival rate (at 106, 130, 178, and $202 \mathrm{~h}$ postexposure) and morphometric characteristics (at 82, 106, 130, 154, 178, and $202 \mathrm{~h}$ postexposure).

\begin{tabular}{|c|c|c|c|c|c|c|}
\hline \multirow[t]{2}{*}{ No. } & \multicolumn{2}{|l|}{ Variables } & \multirow[b]{2}{*}{ Equations } & \multirow[t]{2}{*}{$r^{2}$} & \multirow[t]{2}{*}{$\mathbf{F}$} & \multirow[t]{2}{*}{$p$} \\
\hline & Independent & Dependent & & & & \\
\hline 1 & $\mathrm{APB} / \mathrm{BD} 1-82$ & SR-106 & $y=9.318 x-17.233$ & 0.243 & 12.199 & 0.001 \\
\hline 2 & APB- 82 & SR-130 & $y=-50.637 x+147.456$ & 0.295 & 15.933 & $<0.001$ \\
\hline 3 & APB/HL-106 & SR-130 & $y=30.620 x+39.991$ & 0.242 & 12.165 & 0.001 \\
\hline 4 & BL-82 & $\mathrm{SR}_{\mathrm{SD}}-130$ & $y=12.202 x-23.874$ & 0.251 & 12.705 & 0.001 \\
\hline 5 & BL/BD2-82 & $\mathrm{SR}_{\mathrm{SD}}-130$ & $y=3.566 x-3.731$ & 0.224 & 10.955 & 0.002 \\
\hline 6 & APB-130 & $\mathrm{SR}_{\mathrm{SD}}-130$ & $y=33.155 x-29.478$ & 0.217 & 10.519 & 0.002 \\
\hline 7 & BL/APB-130 & $\mathrm{SR}_{\mathrm{SD}}-130$ & $y=-23.904 x+79.486$ & 0.307 & 16.836 & $<0.001$ \\
\hline 8 & BL/PoPB-130 & $\mathrm{SR}_{\mathrm{SD}}-130$ & $y=64.618 x-88.036$ & 0.282 & 14.959 & $<0.001$ \\
\hline 9 & BL/HL-130 & $\mathrm{SR}_{\mathrm{SD}^{-}} 130$ & $y=-15.635 x+80.156$ & 0.318 & 17.713 & $<0.001$ \\
\hline 10 & APB/PoPB-130 & $\mathrm{SR}_{\mathrm{SD}^{-}} 130$ & $y=64.618 x-23.418$ & 0.282 & 14.959 & $<0.001$ \\
\hline 11 & APB/BD1-130 & $\mathrm{SR}_{\mathrm{SD}^{-}} 130$ & $y=9.857 x-20.775$ & 0.221 & 10.779 & 0.002 \\
\hline 12 & PoPB/HL-130 & $\mathrm{SR}_{\mathrm{SD}}-130$ & $y=-20.869 x+69.919$ & 0.419 & 27.376 & $<0.001$ \\
\hline 13 & APB-82 & SR-178 & $y=-47.663 x+143.670$ & 0.281 & 14.842 & $<0.001$ \\
\hline 14 & APB/HL-106 & SR-178 & $y=28.498 x+43.023$ & 0.225 & 11.058 & 0.002 \\
\hline 15 & BL/APB-178 & SR-178 & $y=33.018 x-8.204$ & 0.293 & 15.751 & $<0.001$ \\
\hline 16 & BL/PoPB-178 & SR-178 & $y=-116.901 x+266.212$ & 0.269 & 14.007 & 0.001 \\
\hline 17 & APB/PoPB-178 & SR-178 & $y=-116.901 x+149.311$ & 0.269 & 14.007 & 0.001 \\
\hline 18 & APB/BD1-178 & SR-178 & $y=-17.196 x+156.305$ & 0.347 & 20.177 & $<0.001$ \\
\hline 19 & $\mathrm{BD} 1 / \mathrm{BD} 2-178$ & SR-178 & $y=212.769 x-51.069$ & 0.436 & 29.335 & $<0.001$ \\
\hline 20 & BL-82 & $\mathrm{SR}_{\mathrm{SD}}-178$ & $y=12.518 x-24.973$ & 0.255 & 13.026 & 0.001 \\
\hline 21 & BL/BD2-82 & $\mathrm{SR}_{\mathrm{SD}^{-}} 178$ & $y=3.688 x-4.456$ & 0.232 & 11.458 & 0.002 \\
\hline 22 & APB-130 & $\mathrm{SR}_{\mathrm{SD}}-178$ & $y=33.696 x-30.301$ & 0.217 & 10.516 & 0.002 \\
\hline 23 & BL/APB-130 & $\mathrm{SR}_{\mathrm{SD}^{-}} 178$ & $y=-24.620 x+81.332$ & 0.315 & 17.497 & $<0.001$ \\
\hline 24 & BL/PoPB-130 & $\mathrm{SR}_{\mathrm{SD}^{-}} 178$ & $y=66.618 x-91.312$ & 0.291 & 15.566 & $<0.001$ \\
\hline 25 & BL/HL-130 & $\mathrm{SR}_{\mathrm{SD}}-178$ & $y=-15.858 x+80.987$ & 0.317 & 17.604 & $<0.001$ \\
\hline 26 & APB/PoPB-130 & $\mathrm{SR}_{\mathrm{SD}^{-}} 178$ & $y=66.618 x-24.693$ & 0.291 & 15.566 & $<0.001$ \\
\hline 27 & APB/BD1-130 & $\mathrm{SR}_{\mathrm{SD}}-178$ & $y=10.042 x-21.541$ & 0.222 & 10.842 & 0.002 \\
\hline 28 & PoPB/HL-130 & $\mathrm{SR}_{\mathrm{SD}^{-}} 178$ & $y=-21.294 x+70.945$ & 0.422 & 27.748 & $<0.001$ \\
\hline 29 & BD1/BD2-178 & $\mathrm{SR}_{\mathrm{SD}-178}$ & $y=-181.086 x+132.195$ & 0.324 & 18.199 & $<0.001$ \\
\hline 30 & APB/BD2-154 & SR-202 & $y=35.084 x-21.934$ & 0.226 & 11.115 & 0.002 \\
\hline 31 & APB-178 & SR-202 & $y=-70.227 x+155.821$ & 0.279 & 14.680 & $<0.001$ \\
\hline 32 & BL/APB-178 & SR-202 & $y=55.139 x-94.015$ & 0.223 & 10.892 & 0.002 \\
\hline 33 & APB/BD1-178 & SR-202 & $y=-29.084 x+182.178$ & 0.270 & 14.087 & 0.001 \\
\hline 34 & PoPB-82 & $\mathrm{SR}_{\mathrm{SD}-202}$ & $y=18.943 x-22.827$ & 0.251 & 12.767 & 0.001 \\
\hline 35 & BL/PoPB-82 & $\mathrm{SR}_{\mathrm{SD}}-202$ & $y=-36.460 x+72.632$ & 0.217 & 10.532 & 0.002 \\
\hline 36 & BL/BD1-82 & $\mathrm{SR}_{\mathrm{SD}-202}$ & $y=6.930 x-41.396$ & 0.330 & 18.680 & $<0.001$ \\
\hline 37 & BL/HL-82 & $\mathrm{SR}_{\mathrm{SD}-202}$ & $y=25.952 x-92.339$ & 0.233 & 11.547 & 0.002 \\
\hline 38 & APB/PoPB-82 & $\mathrm{SR}_{\mathrm{SD}-202}$ & $y=-73.956 x+59.293$ & 0.236 & 11.720 & 0.001 \\
\hline 39 & APB/BD1-82 & $\mathrm{SR}_{\mathrm{SD}-202}$ & $y=20.816 x-48.743$ & 0.302 & 16.477 & $<0.001$ \\
\hline 40 & PoPB/BD1-82 & $\mathrm{SR}_{\mathrm{SD}}-202$ & $y=8.966 x-31.872$ & 0.472 & 33.940 & $<0.001$ \\
\hline 41 & PoPB/HL-82 & $\mathrm{SR}_{\mathrm{SD}}-202$ & $y=15.172 x-25.254$ & 0.282 & 14.921 & $<0.001$ \\
\hline 42 & BD1-106 & $\mathrm{SR}_{\mathrm{SD}}-202$ & $y=-306.699 x+130.108$ & 0.458 & 32.076 & $<0.001$ \\
\hline 43 & BD2-106 & $\mathrm{SR}_{\mathrm{SD}-202}$ & $y=-201.617 x+134.980$ & 0.484 & 35.699 & $<0.001$ \\
\hline 44 & $\mathrm{BL} / \mathrm{BD} 2-106$ & $\mathrm{SR}_{\mathrm{SD}}-202$ & $y=12.392 x-54.872$ & 0.220 & 10.722 & 0.002 \\
\hline 45 & BD1/HL-106 & $\mathrm{SR}_{\mathrm{SD}}-202$ & $y=-203.849 x+106.885$ & 0.323 & 18.095 & $<0.001$ \\
\hline 46 & BD2/HL-106 & $\mathrm{SR}_{\mathrm{SD}}-202$ & $y=-108.658 x+92.748$ & 0.276 & 14.451 & 0.001 \\
\hline 47 & $\mathrm{BL} / \mathrm{BD} 2-154$ & $\mathrm{SR}_{\mathrm{SD}}-202$ & $y=-8.795 x+76.172$ & 0.237 & 11.819 & 0.001 \\
\hline 48 & BL/HL-154 & $\mathrm{SR}_{\mathrm{SD}}-202$ & $y=-23.286 x+110.853$ & 0.261 & 13.408 & 0.001 \\
\hline 49 & PoPB/BD2-154 & $\mathrm{SR}_{\mathrm{SD}-202}$ & $y=-11.512 x+66.119$ & 0.268 & 13.900 & 0.001 \\
\hline 50 & PoPB/HL-154 & $\mathrm{SR}_{\mathrm{SD}}-202$ & $y=-27.205 x+86.438$ & 0.297 & 16.087 & $<0.001$ \\
\hline 51 & $\mathrm{BD} 1 / \mathrm{BD} 2-154$ & $\mathrm{SR}_{\mathrm{SD}}-202$ & $y=-161.830 x+117.985$ & 0.261 & 13.422 & 0.001 \\
\hline 52 & BL/BD2-178 & $\mathrm{SR}_{\mathrm{SD}-202}$ & $y=-19.190 x+159.945$ & 0.294 & 15.852 & $<0.001$ \\
\hline 53 & PoPB/BD2-178 & $\mathrm{SR}_{\mathrm{SD}-202}$ & $y=-23.251 x+130.088$ & 0.253 & 12.878 & 0.001 \\
\hline 54 & BL-202 & $\mathrm{SR}_{\mathrm{SD}}-202$ & $y=-30.154 x+127.305$ & 0.238 & 11.860 & 0.001 \\
\hline 55 & BL/HL-202 & $\mathrm{SR}_{\mathrm{SD}}-202$ & $y=-19.760 x+102.959$ & 0.228 & 11.242 & 0.002 \\
\hline
\end{tabular}


Rows 1, 12, 18-19, 28-30, 33-36, 38-43, 45-47, 49, 51-52, rows 2-11, 13-17, 20-27, 31-32, $37,44,48,50,53-55$, and rows $2,7,9,12-13,16-18,28-29,31,33,35,38,42-43,45-55$ show morphometric characteristics that are correlated to both hatching rate (HR) and survival rate (SR), are only correlated to SR, and are negatively correlated to SR, respectively. $\mathrm{APB}=$ anterior part of body; $\mathrm{BD}-\mathrm{I} / \mathrm{BD}-\mathrm{II}=$ body depths I and II; $\mathrm{BL}=$ body length; $\mathrm{HL}=$ head length; $\mathrm{PoPB}=$ posterior part of body; $\mathrm{SR} \mathrm{SD}=$ standard deviation of survival rate. 